Democratization and Civil Liberties:

The Role of Violence During the Transition

Matteo Cervellati, Piergiuseppe Fortunato, Uwe Sunde

March 2011 Discussion Paper no. 2011-08 


$\begin{array}{ll}\text { Editor: } & \text { Martina Flockerzi } \\ & \text { University of St. Gallen } \\ & \text { School of Economics and Political Science } \\ & \text { Department of Economics } \\ & \text { Varnbüelstrasse } 19 \\ & \text { CH-9000 St. Gallen } \\ & \text { Phone } \quad+41712242325 \\ & \text { Fax } \quad+41712243135 \\ & \text { Email seps@unisg.ch } \\ & \text { School of Economics and Political Science } \\ & \text { Department of Economics } \\ & \text { University of St. Gallen } \\ & \text { Varnbüelstrasse 19 } \\ \text { Publisher: } & \text { CH-9000 St. Gallen } \\ & \text { Phone +41 71 224 23 25 } \\ & \text { Fax } \quad+41712243135 \\ & \text { http://www.seps.unisg.ch }\end{array}$




\section{Democratization and Civil Liberties: The Role of Violence During the Transition}

Matteo Cervellati, Piergiuseppe Fortunato, Uwe Sunde ${ }^{1}$

Author's address:

Prof. Dr. Uwe Sunde

SEW-HSG

Varnbüelstrasse 14

Phone +41712242309

Fax +41712242302

Email uwe.sunde@unisg.ch

Website www.sew.unisg.ch

Matteo Cervellati

University of Bologna and IZA, Bonn

Email m.cervellati@unibo.it

Piergiuseppe Fortunato

UNCTAD, Geneva

Email Piergiuseppe.Fortunato@unctad.org

1 Univesität St. Gallen, IZA Bonn, CEPR London 


\begin{abstract}
This paper investigates the role of violent civil conflicts during the process of democratization for the quality of emerging democracies, and in particular, the protection of civil (political and economic) liberties. A simple theory in which different groups may engage in violent conflict in order to become the ruler predicts a crucial role of the democratization scenario. A peaceful democratization leads to democracies with a high degree of civil liberties, reflecting a social contract according to which all groups are politically represented and the rulers deliberately abstain from wasteful rent extraction. A transition to democracy under a violent conflict is less likely to lead to a system with a high degree of civil liberties. Empirical evidence from the third wave of democratization based on a difference-indifference methodology supports the theoretical predictions. The findings suggest that violent conflicts during the democratic transition have persistent negative effects on the quality of the emerging democracies.
\end{abstract}

\title{
Keywords
}

Democratization, Civil Conflict, Violent Democratization, Civil Liberties.

\section{JEL Classification}

H10, O20, N10. 


\section{Introduction}

The last decades have witnessed an unprecedented wave of transitions to democracy around the world. While in some countries democratization has been essentially peaceful, in others the establishment of democracy was the result of violent social conflicts triggered by the uprising of the politically and economically deprived classes and fueled by failed attempts of repressions. That the transition to democracy follows different paths is by now well documented. ${ }^{1}$ But do these different paths equally pave the way to "good" democracies that lead to significant improvements in political and economic liberties? After discussing at length the occurrence of violence during the democratic transitions of the third wave, Huntington (1993) argues that, even though the role of violence is a priori not obvious, one should expect that consensual, non violent, transitions lead to better democracies. ${ }^{2}$

This paper presents a theoretical and empirical investigation of the role of violence during the transition to democracy for the quality of democracies in terms of their protection of political and economic (civil) liberties. ${ }^{3}$ The theory offers a simple framework where the occurrence of violence during democratization is the result of rational choices within a simple probabilistic conflict model. The politically (and economically) deprived segments of the population can trigger violent conflicts to obtain control over the state apparatus. A civil conflict is observed if the group ruling the state does not give up its power and responds by attempting a violent repression. The politico-economic equilibrium can exhibit different transition scenarios leading to two types of democracies: either the majority gets in control of the state apparatus and exploits it to extract rents by limiting political

\footnotetext{
${ }^{1}$ A large effort has been devoted to the study of the details and modes of democratization, see O'Donnell and Schmitter (1986), Lynn (1990), Remmer (1990), Huntington (1993), Sorensen (1993), Doh (1994), Munck and Leff (1997) and Field (2004), among others.

${ }^{2}$ On page 276 of his book, Huntington (1993) writes "On the one hand, it can be argued that a peaceful, consensual transition favors democratic consolidation. On the other hand, it could also be argued that a violent transition is likely to develop among most population groups a deep aversion to bloodshed and hence to generate a deeper commitment to democratic institutions and values." He also points out, however, that "Overall, it seems more plausible to hypothesize that a consensual, less violent transition provides a better basis". In a similar vein, he notes on page 207 that "Governments created by moderation and compromise ruled by moderation and compromise. Governments created by violence ruled by violence".

${ }^{3}$ Different formal theories of democratization have been recently proposed. As discussed in more details below, these theories do not study the different transition scenarios within the same framework and, accordingly, do not provide predictions about their implications for the emerging democracies. Detailed narratives and investigations on the emergence of violence in the different transition episodes are available especially for the third wave of democratization, see for instance the report by Freedom House (Karatnycky et al., 2005). We are not aware of any systematic econometric investigation based on cross-country panel data of the role of violence during democratization for the quality of democracies, however.
} 
and economic liberties; or these liberties are respected and public policies are the result of a broader consensus among the population. These categories resemble the ones of "mass democracy" (when the poor rule over the rich) and "democracy" described by Lipset (1959).

In the model, the democratic transition as well as the type of emerging democracy are determined endogenously in equilibrium. Factors of production are distributed unequally among the groups of society and economic inequality changes overtime in a dynamic general equilibrium setting. Democratization can either be peaceful (and consensual), or it may follow a violent conflict. ${ }^{5}$ A democracy characterized by a high level of civil liberties can emerge in equilibrium if, and only if, it is optimal for all groups. ${ }^{6}$ The model delivers a simple characterization of the conditions under which each democratization scenario takes place and of its impact on the features of the emerging democracies. While peaceful transitions lead to improvements in political and economic liberties, this is not necessarily the case for democratization following violent conflicts. The paper therefore contributes to the literature studying the structural (economic) determinants of democratization, as well as to the literature on the role of the contingencies of democratization studied in political science. In this respect, the contribution relates to both lines of research by providing a structural account for the emergence of the different democratization scenarios and their consequences for the quality of the emerging democracies. ${ }^{7}$

\footnotetext{
${ }^{4}$ While we consider democracies of different quality, the analysis is related to the consideration of a finer measure of regimes than non-democracy and democracy, as proposed by Epstein et al. (2006), Brownlee (2009), or Goldstone et al. (2010) in different contexts.

${ }^{5}$ Formal theories of democratization studying the different scenarios have been presented in the political economics literature. Theories where democracies arise under (the shadow of) conflict include Acemoglu and Robinson (2000, 2001 and 2006), Conley and Temimi (2001) and Bertocchi and Spagat (2001). The emergence of peaceful democratization (for efficiency reasons) has been formalized by Bourguignon and Verdier (2000), Lizzeri and Persico (2004), Llavador and Oxoby (2005), Jack and Lagunoff (2006a, 2006b), Gradstein (2007), Cervellati, Fortunato and Sunde (2008). To the best of our knowledge, the only available theory that considers the endogenous emergence of different transition scenarios (although without admitting the possibility of open conflicts in equilibrium as studied in this paper) is Cervellati, Fortunato and Sunde (2007), where democratization under a broad consensus can serve as coordination device in a model with multiple equilibria. The formal model presented in the present paper also complements recent conceptual work by North, Wallis, and Weingast (2009) on the interplay between violence and social order in terms of restricted or universal political franchise and the transition between the two.

${ }^{6}$ From this perspective, good democracies are modeled as equilibrium "social contracts". This view of democracy is similar to the concept of self-enforcing democracy proposed in political science by, e.g., Weingast (1997), Przeworski (2005, 2006), and Fearon (2006). By pointing at the role of the transition scenario to democracy, the paper also contributes to the literature on the question whether democratization triggers interstate (or civil) wars, see, e.g., Mansfield and Snyder (1995) or Ward and Gleditsch (1998), and Cederman, Hug, and Wenger (2008) for a survey, and Cederman, Hug, and Krebs (2010) for a recent empirical study.

${ }^{7}$ The results also complement the recent literature on political violence and the emergence of civil conflicts, see, e.g., Besley and Persson (2011), by demonstrating the role of violence during the endogenous emergence of political regimes
} 
In the model the reduction in inequality and the increasing relative importance of human capital are crucial for the emergence of democracy. Economic development does not matter for democratization directly, but indirectly by affecting the control over productive resources and the incentives to engage in conflict across different social groups. The evidence on the causal effect of development on democratization is weak. The available findings suggest an important role of historical factors, country specific characteristics and path dependence for democracy. ${ }^{8}$ Concerning the determinants of the specific transition scenario, the model predicts a key role of some structural features, like the concentration of ownership of productive (natural) resources and the size of the ruling elites, which are affected by geographic and historical country specific characteristics. ${ }^{9}$ As documented below, inequality significantly increases the likelihood of observing violent civil conflicts during democratization in the context of the third wave. ${ }^{10}$ The model also highlights, however, that random events and short term contingencies may also affect the transition scenario by favoring insurgency, the repression ability of the rulers or by affecting the rents controlled by ruler and the costs and benefits of being in power.

In terms of the consequences of democratization, the theory predicts that democratization can lead to a better protection of individual liberties (economic and political) but, more importantly, that and for the cohesiveness of political institutions.

${ }^{8}$ The modernization hypothesis, that follows the arguments by Lipset (1959), predicts a key role of economic development, of a relatively large middle class and a large importance of human capital, for the emergence of democracy. Evidence that increased income per capita favors democratization is provided by Przeworski and Limongi (1997), Barro (1999), and Przeworski et al. (2000), among others. The findings by Przeworski (2004) and Acemoglu et al. (2008), among others, suggest that the effect of income per capita is weak (and in particular it disappears once country fixed effects are taken into account). On the role of changing inequality, Huber et al. (1993) argues that capitalist development historically reduced the importance of land resources thereby eroding the economic and political power of the (landlord) elites. Boix and Stokes (2003) find that the economic prosperity goes hand in hand with the availability of human capital and the portion of farmers in the population, features that capture a reduction in income inequality. The findings of Barro (1991), Easterly (2001) Boix (2003) and Rogowski and MacRae (2008) also suggest a key role of inequality for institutional change but a weak, or absent, direct role of economic development for democratization. We refer to Cheibub and Vreeland (2010) for a comprehensive and critical discussion of the empirical literature on the relationship between development and democratization.

${ }^{9}$ For instance, Engerman and Sokoloff (2001) highlight the role of geography for the modes and types of agricultural production (in terms of crops and size of land ownership) and suggest that exogenous geographical features can explain the larger structural inequality, the larger concentration of political power and the lower levels of education in Latin America compared to the (north of the) United States. These arguments could be compatible with the facts that many Latin American countries, such as Uruguay in 1919, Colombia in 1936, Venezuela in 1945 and Nicaragua in 1979 , experienced democratic transitions with substantial violence.

${ }^{10}$ Evidence on the role of country specific conditions and inequality for civil conflicts is provided by Fearon and Laitin (2003) and Collier and Hoeffler (2004), among others. The available evidence does not explicitly refer to violence during democratization, however. See Blattman and Miguel (2010) for a recent survey. 
the conditions under which democratization takes place are crucial for the quality of the emerging democracy. ${ }^{11}$ This prediction can help rationalize the mixed findings in the literature that suggest that democracies may not be superior per se but that democratization potentially plays an important instrumental role. ${ }^{12}$ The theory supports the view that democratization can affect development indirectly by leading to larger political and economic freedom but suggests that, empirically, it may be relevant to explicitly control for the transition scenario in terms of the level of violence at the outset of democratization. ${ }^{13}$

The main novel testable hypothesis refers to the crucial role of the democratization scenario (in terms of violence) for the "quality" of the emerging democracy that, to the best of our knowledge, has not been empirically investigated before. We test this hypothesis using cross-country panel data for the period 1970-2004 that covers the democratic transitions of the third wave. We consider a dichotomic classification between democracies and non democracies. A categorical classification of the political regime is required to clearly identify the moment of regime transition. This concept of democracy is also consistent with the theoretical model. Nonetheless, as in the theory, within the dichotomous classification, we consider the quality of democracies by accounting for different degrees of political and economic liberties. More specifically, the identification of the effect of democratization exploits information on the different years of (permanent) democratization in panel data with country and time fixed effects. ${ }^{14}$ After documenting a positive effect of democratization on civil liberties (using a difference in difference approach) we further discriminate between violent and non violent democracies.

\footnotetext{
${ }^{11}$ This feature also distinguishes the theory presented above from the literature on democratization and conflict along the lines of Boix (2003) and Acemoglu and Robinson (2006), which is mainly concerned with the determinants of democratization, but remains silent about the emergence of different economic institutions under oligarchies and democracies.

12 The works by Tavares and Wacziarg (2001), Rodrik and Wacziarg (2005) and Papaioannou and Siourounis (2008) have provided evidence for positive effects of democracy or democratization on growth while Barro (2000) and Glaeser et al. (2004) find no evidence for a direct causal effect of democracy on growth.

${ }^{13}$ The empirical findings of Acemoglu et al. (2001), Rigobon and Rodrik (2005), and Rodrik et al. (2004), among others, support the view of an indirect effect of democratization. These works abstract from the empirical role of violence during democratization. The evidence by Flores and Nooruddin (2009) is closer to the model's prediction by documenting that post-conflict democratization retards economic recovery.

${ }^{14}$ In view of the literature on the definition and measurement of regime changes the paper therefore stands halfway between a strictly dichotomous view of democracy (which is needed for the empirical identification) and a more detailed account of regime quality. See also Cheibub, Gandhi and Vreeland (2010) and references therein for a discussion of these issues. As benchmark information on the year of democratization we use the classification provided by Papaioannou and Siourounis (2008) who study the effect of democratization on income per capita growth. As discussed in more details below, this classification follows the literature on the conceptualization and measurement of democracy in particular, Munck and Verkuilen (2002) or Przeworski et al (2000), using information on whether there where free and contested elections, relevant changes in the Freedom House Polity indicator and imposing a five year stability condition.
} 
This provides a direct test of the theoretical prediction by explicitly allowing for a differential effect of violent and peaceful transitions to democracy on civil liberties.

The empirical results suggest that peaceful democratic transitions have a positive and significant effect on the quality of political and economic liberties. In contrast, the effect of violent transitions is significantly weaker or absent. The results are robust to several alternative specifications like the use of different definitions of violence and social conflicts, the inclusion of additional controls like the occurrence of civil conflicts in a particular year (on top of violence during democratization), the past level of civil liberties, the past level and growth of income and the inclusion of region specific growth trends. The empirical findings suggest that accounting for the hitherto largely unexplored role of the transition scenario (and its level of violence) may help explaining while some democracies fail in providing sizable improvements in political and economic liberties.

The paper is organized as follows. Section 2 presents the model. Section 3 characterizes the politico-economic equilibria. Section 4 uses data for the third wave of democratization for the period 1970-2003 to test the prediction on the role of violence during democratization. Section 5 concludes. All analytical derivations and Proofs are relegated to the Appendix.

\section{A Simple Theory of Democratization and Social Conflicts}

Model Set-up. Consider an economy populated by subsequent generations of individuals. Individuals belong to two groups the Elite, $E$, and the People, $P$ having size $\gamma^{E}=\gamma$ and $\gamma^{P}=1-\gamma$ with $\gamma^{E} \leq 1 / 2$. In the following, $i=E, P$ interchangeably denotes an individual and the family or dynasty to which the individual belongs. At each point in time (generation), $t$, each individual $i$ has income $y_{t}^{i}$ with $y_{t}^{E} \geq y_{t}^{P}$. The average (per-capita) income is

$$
y_{t}=\gamma y_{t}^{E}+(1-\gamma) y_{t}^{P}
$$

while the inequality in terms of relative per capita income of the individuals in the two groups is denoted by

$$
\lambda_{t}:=\frac{y_{t}^{E}}{y_{t}^{P}} \geq 1
$$

The emergence and the features of a democratic regime are determined endogenously in the model. At each moment in time $t$, either one of the groups, the "ruling group", controls the state apparatus and extracts income from the "ruled group", or the two groups share incomes more evenly in a democratic "social contract".

Consider first a situation in which one group rules by exploiting the state apparatus to extract resources from the economy. We adopt a simple model of rent extraction where the disposable income 
accruing to the ruling group $i$ is given by

$$
\bar{y}_{t}^{i}=\left[y_{t}^{i}+x \frac{\gamma^{j} y_{t}^{j}}{\gamma^{i}}\right](1-\varphi)
$$

where $x$ is the share of resources of the ruled that is appropriated by the ruling group while $\varphi \in$ $(0,1)$ represents the share of aggregate income which is lost in association to the rent-extraction activities. Symmetrically, members of the ruled group $j$ obtain a disposable income equal to $\underline{y}^{j}=$ $y^{j}(1-x)(1-\varphi) \cdot{ }^{15}$ Notice that both groups, the Elite and the People, can extract resources as in (2) if they control the state apparatus. The formulation in (2) captures some key features in a very simple way. First, the allocation of income across groups is not determined by public policies (like, for instance, fiscal redistribution) where all groups are politically involved (like for instance by voting in free elections) but is the result of a unilateral process of rent extraction by part of the group ruling the state. Second, the process of income redistribution from the ruled to the ruling group is, in principle, unbounded and is only limited by the (exogenous) rent extraction ability of the ruling group $x .^{16}$ These two features capture the idea that the ruling group extracts resources by limiting the political liberties (in terms of voting rights or effective influence on public policies) and economic liberties (in terms of pre-defined protection of claims to property rights income and protection from expropriation by part of the ruler). The third relevant feature is that the process of rent extraction and the associated repression of liberties involves an efficiency cost, $\varphi$. This feature implies that the ruling group faces an effective trade-off between the amount of resources that they can extract and the efficiency costs of limiting liberties of the ruled. In reality, the extraction of resources by part of ruling group can take place either directly, e.g., in terms of rent seeking and coercive expropriation of factors of production, or indirectly, by means of politically controlled state monopolies, arbitrary price regulations, public sector patronage etc. Notice that all these extraction activities ultimately entail the violation of basic civil liberties, through restrictions on the capabilities to make economic investments and reap their returns. By affecting the incentive to work and produce, both direct and indirect extraction activities distort the functioning of the economy and absorb a fraction of income. ${ }^{17}$

\footnotetext{
${ }^{15}$ In the following the variables with an "upperbar" refer to the group that is ruling while the variables with a "lowerbar" refer to the ruled group.

${ }^{16}$ This means, in particular, that the disposable income of the ruled can be ex-post lower than the one of the rulers even if it is ex-ante larger. In principle if $x=1$ then the ruling group can extract all resources by the ruled.

${ }^{17}$ For simplicity, we take the share of resources that can be appropriated, $x$, and the distortions, $\varphi$, to be given exogenously. In reality, these can be at least in part endogenously under the control of the ruling group but can also be related to exogenous country features like, for instance, the availability of lootable natural resources. For illustrative purposes, we assume that the efficiency loss related to expropriation is sufficiently low, in particular $x(1-\varphi)>\varphi$, so that an oligarchic regime where the Elite rules can emerge in equilibrium. The conditions for the emergence of this equilibrium are discussed below and formally studied in the Appendix.
} 
Alternatively, income redistribution can be the result of a political process where all groups are represented and where there are limits to redistribution (that is, there are well defined claims to individual property rights). This equilibrium is denoted "social contract" since, as discussed below, it can emerge only if both groups are politically represented (that is, only if there is universal franchise) and if both groups find it optimal.The allocation of disposable income in this scenario is given by,

$$
\widetilde{y}_{t}^{i}=(1-\tau) y_{t}^{i}+\tau y_{t}
$$

where $\tau \in(0,1)$ is a marginal rate of (progressive) fiscal redistribution. Although we take $\tau$ to be exogenous one could consider it to be determined endogenously according to a voting model. What matters is that (compared to income distribution when the ruling group extracts resources as in (2)), equation (3) involves progressive income redistribution, which is bounded from above. In particular the maximum degree of redistribution would be realized for $\tau=1$ and would involve full equality so that $\widetilde{y}_{t}^{i}=y$ for all $i$. Without any loss of generality, we set $\tau=1$ as the benchmark in the following. ${ }^{18}$ Compared to (2) the social contract involves a better protection of political liberties (in terms of influence over redistribution policies) and economic liberties (in terms of bounds over redistribution or protection to property rights). We also assume that redistribution in democracies involves a lower degree of distortions of economic activities. This assumption can be justified in view of the fact that in a social contract redistribution is realized results from a political process in which all groups have a say (and which is therefore more consensual), is realized with formal democratic institutions and is not unlimited. ${ }^{19}$ Finally, we assume that a social contract can emerge only in democracies. This assumption is made since the goal is to investigate the implications of different types of democratic transitions rather than comparing democracies and non democracies. Considering bounds on the extent to which fiscal redistribution can be regressive does not affect the predictions about the role of democratization, but would enable the emergence of a social contract with a partial protection of civil liberties even in non democratic regimes. ${ }^{20}$

\footnotetext{
${ }^{18}$ As discussed below, the actual level of redistribution $\tau$ is irrelevant for the qualitative predictions of the model. One could also consider voting over redistribution in direct democracies a la Meltzer and Richard (1981) or in a model of probabilistic voting.

${ }^{19}$ For simplicity we set the distortion in the social contract to zero but all results only require that they are lower than in the rent extraction case. The predictions can be derived under much milder assumptions since what is needed for the argument is only that fiscal redistribution is more progressive under a democracy compared to an oligarchy which insures that a democratization involves foregone income for the Elites. The idea that democratization involves a more progressive redistribution goes back to De Tocqueville (1835) and is in line with empirical and historical evidence, see, e.g., Tavares and Wacziarg (2001).

${ }^{20}$ The related question of relative efficiency of oligarchies and democracies is studied theoretically in Cervellati et al. (2008) and empirically in Sunde et al. (2008).
} 
This simple set up highlights the central mechanism of the model. The extension of the political franchise (the voting rights) regards the allocation of de jure power. In the model, a political regime is democratic if (at least) a majority of the population has voting rights. In turn, the control of the state apparatus gives de facto power to the ruling group which can extract part of the income by limiting political and economic liberties of the ruled population but with an efficiency cost. Accordingly, equilibria where the ruling group extract resources by limiting civil liberties of the other group may emerge both in oligarchies (where the de jure power is limited to the Elite) and in democracies (even with universal voting franchise). The alternative equilibrium sees both groups sharing the de jure power (with a universal political franchise) and the de facto power (in terms of control of the state) by distributing income following a social contract characterized by a larger protection of political and economic liberties. This set up gives rise to three possible distinct equilibria that closely resemble the regimes described by Aristotle (1992) in his Politics, where he distinguishes between an oligarchy, a democracy (in the sense of the people dominating the state) and a constitutional government (politeia), which reflects the social contract in which all groups of society cooperate in political decisions. These notions are also closely related to those of Lipset (1959), who distinguishes oligarchy (when the rich rule over the poor), mass democracy (when the poor rule over the rich), or democracy (when both groups have related interests and respect each other on the basis of the allocation of de jure power). These distinctions can also be related to the idea of a tyranny of the majority in democracies which goes back to de Tocqueville (1835).

Probabilistic Conflicts. The ruled may engage in a violent conflict for the control of the state apparatus. Consider a simple probabilistic set-up where, in case of conflict, each group wins with a probability

$$
\pi_{t}^{i}=\frac{\gamma^{i} y_{t}^{i}}{y_{t}} \text { for each } i=E, P
$$

The winning probability (4) is increasing in the share of income controlled by each group, $\gamma^{i} y_{t}^{i}$. The winning probability can be equivalently interpreted as being increasing in the conflict potential which depends on the group income $y^{i}$ (e.g. the number of guns that can be bought) and the group size $\gamma^{i}$ (e.g. the number of gunners). ${ }^{21}$

Failed attempts to obtain the control of the state apparatus by engaging in violent conflicts are costly. For simplicity, we assume that the group that triggers an unsuccessful conflict looses a share $c \in[0,1]$ of its income. This cost can be interpreted as either a direct cost associated with the the

\footnotetext{
${ }^{21}$ We abstract from the consideration of asymmetric winning probabilities related to the current allocation of de facto power. The results would change only quantitatively, but not qualitatively, by explicitly considering an advantage in conflict for the group controlling the state apparatus like, e.g., the army. Also, for simplicity, we abstract from modeling endogenous fighting efforts.
} 
defeat in an open struggle, or resulting from the repression or retaliation by part of the ruling group. Technically, the existence of some costs for triggering and loosing conflicts ensures that violence does not always emerge in equilibrium. ${ }^{22}$

Timing. In each generation, the equilibrium is the result of a game with the following sequence of moves:

1. The ruling group decides whether to exploit its de facto power and extract resources from the economy or offer a social contract under democracy; ${ }^{23}$

2. The ruled decide whether to accept the offer of a social contract (if made by the ruler), acquiesce to be ruled (if no social contract is offered) or trigger a violent conflict [which is won by each group with a probability given in (4)];

3. In case of social conflict: the winner can rule by force and expropriate the loser, or offer a social contract under democracy. A social contract emerges in equilibrium only if both groups agree.

This timing explicitly states that for a social contract to emerge, both groups need to agree in preferring it to a violent conflict or a rule by force. This simple framework implies that the incentives to start a violent conflict depend on the probability of success (which depends on both relative size and income of the different groups), the cost of defeat and, in particular, the allocation of income that will emerge after the end of the conflict, and therefore on the emergence (or lack) of a social contract. Consequently, the control of the state, the observation of violent conflicts and the quality of democracies need to be characterized jointly in equilibrium.

Income Production and Income Distribution. To illustrate the source of income inequality and its change overtime, consider the following simple model of income production. Each generation of individuals $t$ has size $L \equiv 1$ and has a stock of natural resources (or land) $N_{t}=N$, human capital $H_{t}$ and labor $L_{t}=1$ at its disposal. ${ }^{24}$ Factors of production are used in the aggregate production function $Y_{t}=Y\left(A_{t} H_{t}, L, N\right)$ where $A_{t}$ denotes a human capital augmenting technological parameter.

\footnotetext{
${ }^{22}$ To ensure that conflicts can emerge under certain conditions, but are not always a dominant strategy, the cost for loosing a conflict must be sufficiently large compared to the gain from expropriation. As shown in the Appendix, this is the case if $c>\frac{x}{1-x}$.

${ }^{23}$ Strictly speaking, if the Elite rules they also have the option to give up the control of the state without offering a democratic social contract. As studied below, the strategy cannot be optimal in equilibrium, however.

${ }^{24}$ In principle, one could explicitly investigate the process of human capital acquisition. The income lost in the economy due to rent extraction by part of the ruler, the variable $\varphi$ in equation (2) above, could be related to distortions in the investments in human capital due to the low protection of individual claims to private investments, or due to higher
} 
All agents are endowed with $h_{t}$ units of human capital and one unit of (homogeneous) labor but, as benchmark, all available natural resources $N$ are equally distributed only among the the members of the elite $E$, so that $n_{t}^{E}=N / \gamma$, while for the people $n_{t}^{P} \equiv 0 .{ }^{25}$ Factor incomes from supplying endowments to the market are given by $y_{t}^{i}=w_{t}+r_{t} h_{t}^{i}+\rho_{t} n^{i}$ for all $i=E, P .{ }^{26}$ Since the Elite controls (a larger share of) natural resources we have $y_{t}^{E} \geq y_{t}^{P}, \forall t$. As engine of economic growth and changes in income inequality, we consider a reduced form endogenous technological progress that depends on the stock of human capital so that $A_{t}=A_{t-1}\left(1+a\left(H_{t-1}\right)\right)$ with $a\left(H_{t-1}\right)$ being a (weakly) monotonically increasing function such that, $a^{\prime}(\cdot) \geq 0 .{ }^{27}$ Finally assuming that human capital and natural resources are substitutes implies that the available stock of human capital in a given generation indirectly makes human capital a more important source of income, relative to natural resources, in the future. The technical progress therefore leads to progressive reduction in income inequality (as discussed in more details below) which is associated to a process of erosion of conflict potential of the Elite. ${ }^{28}$

\section{Democratization and the Transition Scenario}

This section presents the main results. In Section 3.1 we study the conditions under which both groups benefit from a social contract and the conditions under which the threat of violent conflicts are credible. Section 3.3 characterizes the dynamic evolution of the economy, the different transition scenarios to democracy, and their implications for the features of the emerging democracies.

\subsection{Equilibrium social contract conditional on the identity of the ruler.}

Let us abstract for the moment from the possibility of violent conflicts and concentrate attention on the emergence of a peaceful social contract for a given allocation of de facto power, that is, conditional levels of entry barriers in oligarchies as in Acemoglu (2008). Since our focus is on studying the implications of different democratization scenarios, we consider distortions in reduced form for simplicity.

${ }^{25}$ The assumption that the people own no land is without loss of generality. All that is required for the analysis is some inequality in terms of resource endowments between elite and people.

${ }^{26}$ Factor prices are determined on the market and equal marginal productivity: $w_{t}=\partial Y_{t} / \partial L, r_{t}=\partial Y_{t} / \partial H_{t}$ and $\rho_{t}=\partial Y_{t} / \partial N$.

27 This formulation is in line with the endogenous growth literature where the human capital acquired by one generation exerts an externality on productivity of the next generation, see, e.g., Nelson and Phelps (1966). Any formulation implying a positive relationship between human capital and technological progress is equivalent for the results.

${ }^{28}$ An example of a neoclassical production function satisfying these assumptions is $Y_{t}=\left(A_{t} H_{t}+N\right)^{\alpha}\left(L_{t}\right)^{1-\alpha}$, with $0<\alpha<1$. Equivalently one could adopt a technology with one commodity being produced in two sectors, with labor being optimally allocated across sectors like, e.g. $Y_{t}=Y_{t}^{T}+Y_{t}^{M}=N^{\alpha} L_{t}^{T 1-\alpha}+\left(A_{t} H_{t}\right)^{\alpha}\left(L_{t}^{M}\right)^{1-\alpha}$, where sector $T$ is natural resource intensive while sector $M$ is human capital intensive. 
on the group being in control over the state. This is equivalent to characterizing the conditions under which the social contract emerges in equilibrium being supported by both groups and without any credible threat of conflict.

Recall that, by assumption, a social contract may emerge as an equilibrium only under a democratic regime. The conditions for the emergence of a social contract in equilibrium depend on the identity of the ruler, that is, on whether the state apparatus is under the control of the Elite or the People. Consider first the case in which the Elite have de facto power. In this case, the Elite must compare the disposable income that they would receive under a democratic social contract with what they could obtain by over-ruling the political and economic liberties of the ruled population and by exploiting the state apparatus to extract resources from the economy. From (2) and (3), the Elite prefer a democratic social contract if, and only if,

$$
\left(y_{t}^{E}+x \frac{(1-\gamma)}{\gamma} y_{t}^{P}\right)(1-\varphi) \leq y_{t}
$$

For the People a social contract under democracy is better than being ruled if, and only if,

$$
y_{t}^{P}(1-x)(1-\varphi) \leq y_{t}
$$

Notice that if condition (5) holds then condition (6) is redundant since $y_{t}^{E} \geq y_{t}^{P}$. Consequently, whenever an unchallenged Elite that is in control of the government finds the social contract profitable the same is true also for the People. Recall that $\lambda=y^{E} / y^{P}$ reflects income inequality, and denote by $\bar{\Lambda}_{E}(\gamma)$ the level of $\lambda$ that solves the condition (5) with equality. ${ }^{29}$ The function $\bar{\Lambda}_{E}(\gamma)$ represents the combinations of $\gamma$ and $\lambda$ for which the members of the Elite receive the same income under a democratic social contract or by exploiting their de facto power to extract resources from the economy. This locus is upward sloping in the $(\gamma, \lambda)$-space since a larger $\gamma$ implies a smaller group of people and, for any given inequality $\lambda$, a higher per capita income in democracies, $y$. In other words, a larger $\gamma$ implies that a democratic social contract is less costly in terms of redistribution for the Elite, leading to a larger level of income inequality $\lambda$ for which the members of the Elite receive the same income with and without the social contract. For any level of income inequality $\lambda>\bar{\Lambda}_{E}(\gamma)$, the Elite is better off by being the ruling group even if this comes at the cost of imposing distortions on the economy.

If the People are the ruling group then a social contract can emerge in equilibrium if, and only if,

$$
\left[y_{t}^{P}+x \frac{\gamma}{1-\gamma} y_{t}^{E}\right](1-\varphi) \leq y_{t}
$$

and

$$
y_{t}^{E}(1-x)(1-\varphi) \leq y_{t}
$$

\footnotetext{
${ }^{29}$ The formal derivation of the function $\bar{\Lambda}_{E}(\gamma)$ and of its shape is relegated to the Appendix.
} 
Conditions (7) and (8) must hold jointly to make a social contract feasible in equilibrium. When the People rule, the two groups have to solve different trade-offs. In this case, the fact that the people prefer a social contract does not automatically imply that the same is true for the Elite since they face two alternative costs: they may accept the social contract (and transfer part of their income to the people) or reject it and retain the disposable income that is left net of the distortions and the rent extraction by the rulers. Solving again for $\lambda$ from (7) and (8) gives the levels of income inequality $\lambda$ as function of $\gamma$ for which the People, respectively the Elite, are indifferent between an equilibrium with and without a social contract and rule of law. Denote these functions as $\bar{\Lambda}_{P}(\gamma)$ and $\underline{\Lambda}_{E}(\gamma)$, respectively. ${ }^{30}$ The gains (respectively losses) in a democracy with a social contract increase with income inequality $\lambda$ for the People but decrease for the Elite. For low levels of inequality, i.e., $\lambda<\bar{\Lambda}_{P}(\gamma)$, the Elite would accept a peaceful social contract but the People prefer extracting resources from the economy. On the contrary, when inequality is large, i.e. $\lambda>\underline{\Lambda}_{E}(\gamma)$ the Elite prefer to face the income losses to a coercive state apparatus controlled by the People in a democracy with little civil (political and economic) liberties.

The thresholds for the emergence of the social contract, when the Elite and the People rule, are depicted in Graph 1 below.

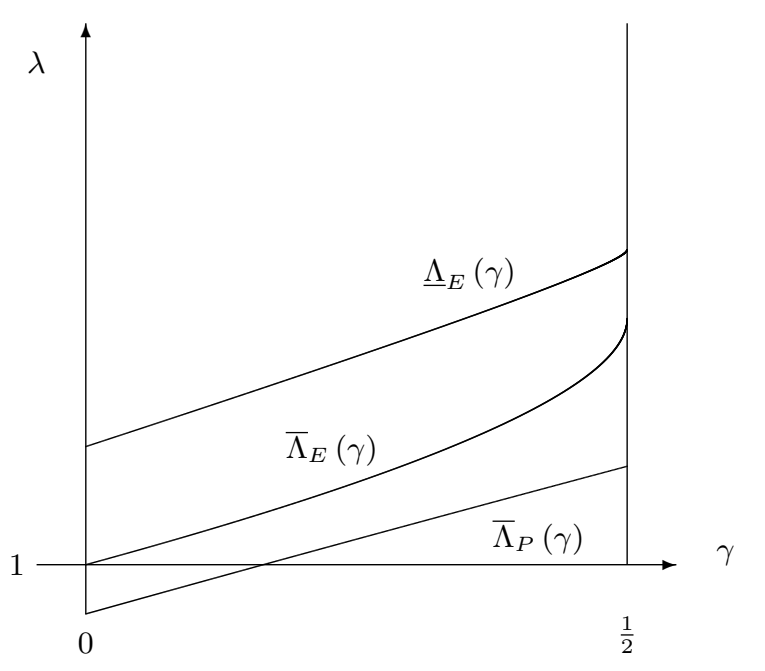

Graph 1. Equilibrium Social Contract and Identity of Ruler

The functions $\bar{\Lambda}_{E}$, and $\underline{\Lambda}_{E}$ are upward sloping in the $(\gamma, \lambda)$-space since, for a given $\lambda$, a larger $\gamma$ implies a average higher per capita income $y$. Also, $\underline{\Lambda}_{E}$ lies above $\bar{\Lambda}_{E}$ since for any given level of inequality $\lambda$ the net income that the members of the Elite obtain when they are ruled by the People is

\footnotetext{
${ }^{30}$ The formal derivation of $\bar{\Lambda}_{P}$ and $\underline{\Lambda}_{E}$ and the analysis of their respective shapes is relegated to the Appendix. Recall that the "upperbar" and "lowerbar" notation of these functions denotes that the Elite are the ruling group or the ruled group, respectively.
} 
strictly lower than the one they obtain when they have the control of the state apparatus. Therefore, for any given $\lambda$, the value of $\gamma$ that makes the Elite indifferent between the adhering or rejecting a social contract is smaller if they are ruled (since for any $\lambda$, a smaller $\gamma$ corresponds to a lower per capita income $y$ ).

The function $\bar{\Lambda}_{P}$ making the ruling People indifferent is upward sloping in the $(\gamma, \lambda)$-space. When the size of the Elite $\gamma$ is small the People generally prefer to implement a social contract rather than paying the cost of distortions and extracting resources by exploiting their control of the state. Nonetheless, for any given $\lambda$, an increase in $\gamma$ increases the amount of resources that can be extracted by the People. Consequently a larger $\gamma$ implies that a democratic social contract where all groups are politically represented is less convenient vis-a-vis exploiting the control of the state apparatus, which implies that a larger level of income inequality $\lambda$ is required to make the People indifferent between exploiting their control of the state apparatus, or respecting a democratic social contract. This discussion is summarized in,

Proposition 1 (Emergence of Social Contract conditional on Ruler's identity). A democratic social contract emerges in equilibrium if, and only if,

- $\lambda \leq \bar{\Lambda}_{E}(\gamma)$ when the Elite have de facto power;

- $\bar{\Lambda}_{P}(\gamma) \leq \lambda \leq \underline{\Lambda}_{E}(\gamma)$ when the People have de facto power;

The previous analysis lays the ground for the possibility that a social contract emerges not only when the People are in control of the state apparatus but also when the ruling Elite prefer a democratic social contract where all groups are politically represented and are granted their economic claims (net of fiscal redistribution), compared to an oligarchy where the extraction of resources under elitist rule is excessively wasteful.

\subsection{Credible threats of Violent Conflict.}

The analysis so far has abstracted from the possibility of violent conflicts. This is analyzed next by characterizing the incentives of the ruled group for triggering a violent conflict to obtain control over the state apparatus and the incentives of the ruler for attempting a repression. Before that, we investigate the conditions under which the threat by the ruled group of recurring to violent conflict is credible.

Let us consider as status quo the case in which the Elite has the control of the state apparatus and use it to extract resources in an oligarchic regime. As discussed below this is the equilibrium that will 
emerge endogenously in the early stages of economic development. The ruling Elite faces a credible threat if, and only if, the payoff that the People expect by engaging in a violent conflict is higher than the payoff they would obtain by acquiescing to be ruled. We assume that decisions to trigger conflict are fully rational and forward looking and restrict attention to equilibria in which expectations are correct ex-post. ${ }^{31}$

Recall that a violent conflict that fails to change the identity of the ruler is costly for the group that triggered it. In turn, a successful conflict always insures a payoff that is larger than the payoff from acquiescing to be ruled irrespective of whether a social contract will be implemented or not, since the lowest payoff is obtained by the People when they are ruled. Whether a threat of conflict is credible depends on whether the people make use of their newly acquired de facto political power to extract resources or to implement a social contract in a democracy, however. We therefore need to separately investigate the payoff of conflicts with and without the emergence of a social contract.

Consider first the case in which, after a conflict leading to a change in the ruling group identity, no social contract emerges. The expected payoff of violent conflict to the People in this case is,

$$
E \widetilde{y}_{t}^{P}=\pi^{E}\left[\underline{y}^{P}(1-c)\right]+\left(1-\pi^{E}\right)\left[y^{P}+x \frac{\gamma y^{E}}{1-\gamma}\right](1-\varphi)
$$

where $\underline{y}^{P}=y^{P}(1-x)(1-\varphi)$ is the net income received by the people if they are ruled. Recall that $c \in(0,1)$ is the cost of a lost violent conflict, $\pi^{E}$ is the winning probability given in (4), $x$ is the share of income that the ruling group can expropriate and $\varphi$ is the distortion due to the exertion of coercive power by part of the ruling group associated with the limitation of political and economic freedom of the ruled. The expected payoff of conflict must be compared with the income the People would obtain by acquiescing to be ruled by the Elite, $\underline{y}^{P}$, given in (6). The locus $\lambda=\Upsilon(\gamma)$ collects the combinations of $\gamma$ and $\lambda$ for which the People are indifferent between accepting the rule of the Elite and initiating a conflict in order to obtain the control of the state, that is, for which (9) equals (6). When $\lambda \leq \Upsilon(\gamma)$ the threat of a violent conflict is credible. ${ }^{32}$

Consider next the case in which the conflict is followed by the implementation of a social contract. In this case the expected payoff for the People is

$$
E \widetilde{y}_{t}^{P}=\pi^{E}\left[\underline{y}^{P}(1-c)\right]+\left(1-\pi^{E}\right) y,
$$

which again has to be compared to the payoff obtained by acquiescing to the rule of the Elite, $\underline{y}^{P}$ as in

\footnotetext{
${ }^{31}$ This essentially implies restricting attention to the sub-game perfect Nash equilibria of the game with the timing described above.

${ }^{32}$ The locus $\Upsilon(\gamma)$ is characterized in the Appendix. Notice that a credible threat does not automatically lead to a violent conflict in equilibrium since, as studied below, an Elite exposed to a credible threat may, or may not, optimally decide to give up their de facto power and not to attempt a repression to avoid an open struggle.
} 
(6). The locus $\Psi(\gamma)$ collects the combinations of $\gamma$ and $\lambda$ for which the People are indifferent between accepting the rule of the Elite and initiating a conflict in order to implement a social contract, that is, for which (10) equal (6). In this case the threat of conflict is credible if, and only if, $\lambda \geq \Psi(\gamma)$ as studied in the Appendix.

Proposition 2 (Credible Threat of Violent Conflicts). The threat of a violent conflict against the ruling Elite is credible if, and only if,

- $\lambda \leq \Upsilon(\gamma)$ when the People expect to rule in the absence of a social contract;

- $\lambda \geq \Psi(\gamma)$ if a social contract emerges after the conflict.

The shape and position of these loci is determined by parameter values. We restrict attention the case in which the costs associated with an open conflict are higher than the rent-seeking under oligarchy since, otherwise, triggering a conflict would always be a dominant strategy and the threat of violent conflict would always be credible. ${ }^{33}$ The function $\Upsilon(\gamma)$ is monotonically decreasing. For the People, the probability of winning a conflict decreases with the size of the Elite $\gamma$, and with the level of income inequality $\lambda$. Consequently, a larger $\gamma$ implies a reduction in the expected gain of conflict, leading to a lower level of income inequality $\lambda$ for which the members of the People are indifferent between triggering a violent conflict and accepting the rule of the Elite. In turn, the function $\Psi(\gamma)$ is monotonically increasing in $\gamma$. The reason is that the democratic social contract with progressive redistribution becomes more appealing for the People when the level of income inequality $\lambda$ increases. If they expect a social contract to be in place in a democracy, the People are therefore willing to run the risk of an open conflict for lower winning probabilities since the expected gains are higher. Consequently, for increasing $\lambda$ they are indifferent between going to conflict or not for a lower size of the group, that is a higher $\gamma$.

The two thresholds that identify the credibility of a threat of violent conflict are depicted in Graph 2 below. Notice that the existence of a credible threat do not necessarily lead to violent conflict, however, since the ruling group may optimally decide to give up their power to prevent violence, or deliberately decide to attempt a repression and face the lottery of a violent conflict as studied below.

\footnotetext{
${ }^{33}$ The parametric restrictions are characterized in the Appendix. As discussed there restricting attention to this case leaves the qualitative predictions unchanged and is done only to easy illustration.
} 


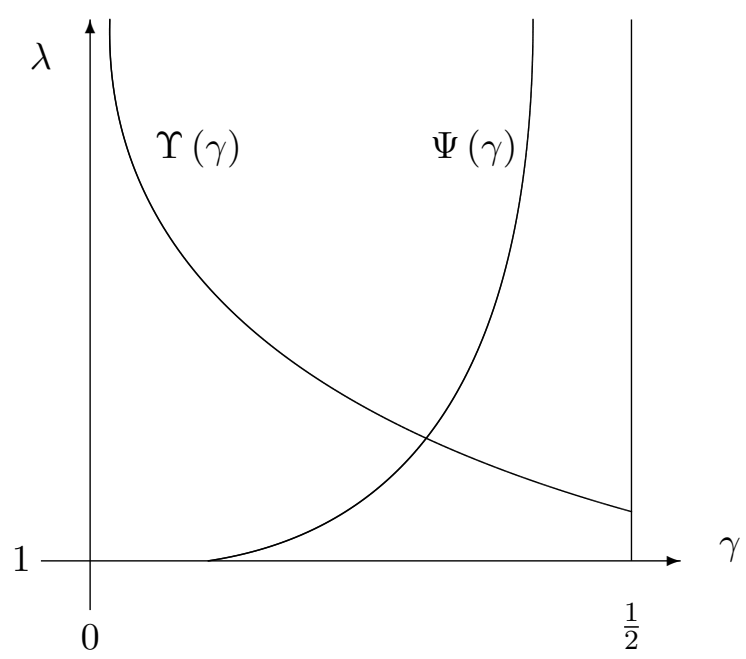

Graph 2. Credible Threats of Violent Conflict

Unchallenged Oligarchy as Equilibrium. Before studying the process of democratization it is useful to first identify the conditions for the emergence of an "oligarchic" equilibrium where the Elite controls the state apparatus without facing any credible threat of violent conflict. These conditions follow as a direct corollary of Proposition 1, which characterizes the the emergence of a democratic social contract conditional on the identity of the ruler, and Proposition 2, which characterizes the credible threat of conflict for being the ruling group conditional on the emergence of a democratic social contract.

From Proposition 1 if the Elite are the rulers, no social contract can emerge in democracies above the locus $\underline{\Lambda}_{E}(\gamma)$. From Proposition 2, the threat of a violent conflict is credible only below the locus $\Upsilon(\gamma)$ in this region. Hence in the area above the two loci $\underline{\Lambda}_{E}(\gamma)$ and $\Upsilon(\gamma)$ an oligarchic Elite in control of the state has no incentives to adhere to a democratic social contract and, at the same time, faces no credible threat of loosing their power by means of violent conflicts.

Graph 3 below depicts the relevant loci for Proposition 1 as bold lines.

This discussion is summarized in,

Corollary 1 (Unchallenged Oligarchy as Equilibrium). If

$$
\lambda>\max \left\{\Upsilon(\gamma), \underline{\Lambda}_{E}(\gamma)\right\}
$$

then the equilibrium is characterized by an oligarchic Elite ruling unchallenged, that is, in the absence of any credible threat of conflict by part of the ruled people.

The previous Corollary essentially states that, for any given $\gamma$, the economy is characterized by an oligarchic equilibrium in which the Elite exploit their de facto power to extract rents from the economy if the share of income controlled by the Elite, $\lambda$, is sufficiently large. 


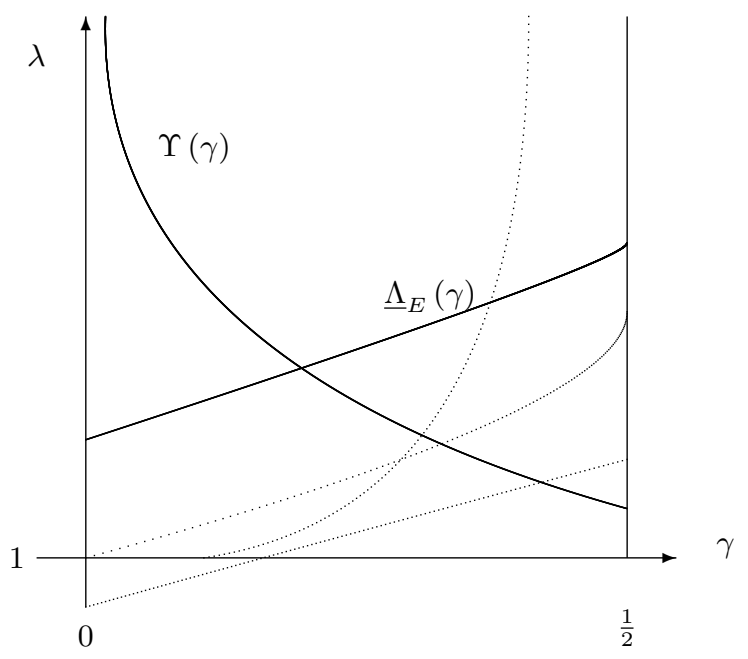

Graph 3. Oligarchy as Equilibrium

\subsection{Democratization Scenario and Social Conflicts}

We finally study the process of democratization and the implications of violent transitions for the features and quality of the emerging democracy. In order to do this, we need to investigate the conditions under which a social contract is feasible in a democracy, the threat of triggering a conflict by part of the People is credible and the Elite has incentives to accommodate the change in political regime or engage in an open fight.

The assumed substitutability between human capital $H$ and natural resources $N$ in the aggregate production function and the dynamics of the technological progress imply that the rents to natural resources decrease during the process of development. ${ }^{34}$ Consequently, the share of income produced by (and distributed to the owners of) natural resources decreases overtime and eventually converges to zero, unlike the shares of income produced by labor and human capital. As a result, income inequality decreases overtime and vanishes in the limit,

Lemma 1. Income inequality $\lambda_{t}$ decreases monotonically overtime with $\lim _{t \rightarrow \infty} \lambda_{t}=1$.

Consider a sufficiently underdeveloped economy, that is, an economy where the productivity of human capital $A_{t}$ is sufficiently low so that natural resources represent an important source of income. Notice that since the Elite is assumed to control a relatively larger share of natural resources than the People, by making the productivity of human capital sufficiently small one can make relative income

\footnotetext{
${ }^{34}$ For example, in the case of the previously cited production function $Y_{t}=\left(A_{t} H_{t}+N\right)^{\alpha}\left(L_{t}\right)^{1-\alpha}$, with $0<\alpha<1$, the rents on natural resources, are given by $\rho_{t}=\alpha\left(A_{t} H_{t}+N\right)^{\alpha-1} L^{1-\alpha}$ so that $\partial \rho_{t} / \partial A_{t}<0$ and $\lim _{A \rightarrow \infty} \rho_{t}=0$.
} 
of the groups $\lambda$ large. From Corollary 1 an economy with a large enough inequality is characterized by an oligarchy ruling unchallenged.

The subsequent reduction of income inequality associated with the increase in the importance of human capital and Lemma 1 imply that for any given $\gamma$, the development of the economy overtime takes place on a vertical trajectory in the $\{\gamma, \lambda\}$ space. $^{35}$ Recall that the functions determining the feasibility of the social contract $\left(\bar{\Lambda}_{E}, \bar{\Lambda}_{P}\right.$ and $\left.\underline{\Lambda}_{E}\right)$ that relate $\lambda$ to $\gamma$, also depend on the distortions due to the lack of social contract $\varphi$ and on the share of income that can be extracted by the ruler, $x$. The same is true for the functions characterizing the credibility of threats of violent conflicts $(\Upsilon$ and $\Psi$ ), which also depend on the cost of being defeated, $c$. The position of these loci in the $\{\gamma, \lambda\}$ space therefore depends on these parameters (as characterized in details in the Appendix), but the explicit dependence on these variables in the notation of the loci is omitted only to simplify illustration. Denote by $\underline{\gamma}(c, x, \varphi)$ the unique level of $\gamma$ at which the two loci $\Upsilon$ and $\underline{\Lambda}_{E}$ cross and by $\bar{\gamma}(c, x, \varphi)$ the unique level of $\gamma$ at which the loci $\underline{\Lambda}_{E}$ and $\Psi$ cross. These thresholds are depicted in Graph 4, which also summarizes the full taxonomy of democratization that is discussed next.

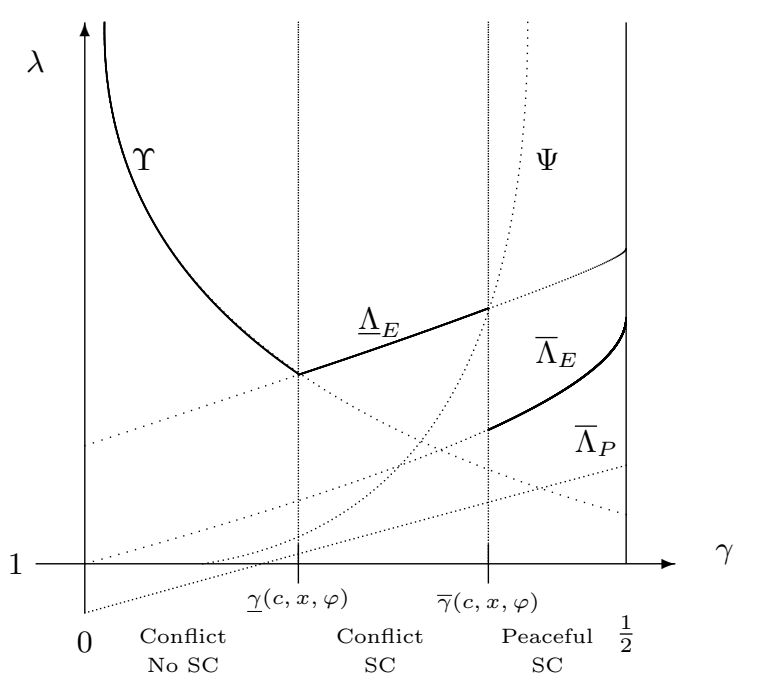

Graph 4. Democratization, Violence and the Social Contract

Consider first an economy with $\gamma<\underline{\gamma}(c, x, \varphi)$. In such an economy, the threat of conflict becomes credible as soon as $\lambda_{t} \leq \Upsilon(\gamma)$, that is, when $\lambda$ is below the function $\Upsilon(\gamma)$ [depicted as a bold line in Graph 4 for $\gamma<\underline{\gamma}(c, x, \varphi)]$. For larger $\lambda$ the Elite is too strong and engaging in a violent conflict is not profitable for the ruled People. From the previous analysis notice next that the Elite is not willing to accept a social contract even in the case of defeat at least as long as $\lambda \geq \underline{\Lambda}_{E}(\gamma)$. Furthermore, the

35 The main predictions of the model do not depend on the monotonous decline in inequality, but this assumption simplifies the illustration of the taxonomy of democratic transitions that is presented next. 
ruling Elite is unwilling to give up the power to avoid an open struggle under these conditions when facing a credible threat of conflict (as formally proved in the Appendix). The reason is that by fighting the conflict the Elite has a positive probability of staying in power. Consequently, for $\gamma<\underline{\gamma}(c, x, \varphi)$, the progressive reduction in inequality eventually leads to open social conflicts which, in case of success of the People, lead to a change in the control of the state apparatus. Despite the fact that the new regime ensures political power to the majority of previously disenfranchised People it does not lead to a social contract, however. The emerging regime is, formally, a democracy since the majority has both de jure power of voting and the de facto control of the state apparatus. Nonetheless, it represents a low quality democracy (or mass democracy using the terminology discussed above), since the masses rule by extract resources in the absence of a social contract.

Consider next $\underline{\gamma}(c, x, \varphi) \leq \gamma \leq \bar{\gamma}(c, x, \varphi)$. From Proposition 1 it follows that the Elite would accept a democratic social contract as soon as $\lambda_{t} \leq \underline{\Lambda}_{E}(\gamma)$, but only if the People are the rulers. If $\lambda_{t}>\bar{\Lambda}_{P}(\gamma)$ also the People would prefer a social contract. From Proposition 2 this makes the threat of conflict credible for any $\lambda_{t} \leq \underline{\Lambda}_{E}(\gamma)$ since the relevant condition $\lambda \geq \Psi$, which characterizes a credible threat of conflict if a social contract is implemented after the conflict, holds. Consequently as soon as $\lambda_{t} \leq \underline{\Lambda}_{E}(\gamma)$ the Elite faces a serious threat of violent conflict in this region. The Elite anticipates that if they loose the conflict they will be offered a social contract since this is the best option for the People. They also know that, being defeated, they will accept. In turn, if they win they will continue to rule in an oligarchy. The mere threat of conflict is not sufficient to induce the Elite to give up their power without fighting, however, as formally shown in the Appendix. In this region the Elite agrees to a democratic social contract only after loosing de facto power in a violent conflict. The occurrence of an open violent conflict therefore represents a necessary condition for the emergence of a democracy implementing a social contract in this region of $\gamma \cdot{ }^{36}$ In this transition scenario the ruling Elite are not willing to voluntarily give up the power but, if defeated, prefer a democratic social contract to be ruled by the People.

Finally, in the region $\gamma>\underline{\gamma}(c, x, \varphi)$ the Elite is better off with a democratic social contract as soon as $\left.\lambda_{t} \leq \underline{\Lambda}_{E}(\gamma)\right)$ when the People are the ruling group but only if $\lambda_{t} \leq \bar{\Lambda}_{E}(\gamma)$ when the Elite rule. For $\Upsilon(\gamma) \leq \lambda_{t}<\Psi(\gamma)$ the threat of conflict is non credible and the Elite rules unchallenged. In this region, the Elite therefore finds it profitable to support a democratic social contract when $\lambda_{t} \leq \bar{\Lambda}_{E}(\gamma)$ (which is depicted as a bold line for $\gamma>\underline{\gamma}(c, x, \varphi)$ in Graph 4). Notice that in this case the Elite finds it more profitable to have a social contract in place even if they could retain the control of the state

\footnotetext{
${ }^{36}$ Notice that this prediction is different from the predictions by Acemoglu and Robinson (2006) where the mere credible threat of conflict is sufficient to induce democratization so that, in equilibrium, no social conflict should be ever observed.
} 
apparatus and rule unchallenged. The reason is that inequality (and the implicit cost of a democratic social contract) is sufficiently low compared to the distortions associated with resource extraction. At this stage for the Elite accepting, or even actively promoting, a peaceful transition leading to a democracy where economic and civil liberties are granted to all individuals is the best option. Recall that whenever the groups fail to agree to a social contract, an efficiency loss in terms of a share $\varphi$ of income accrues, which makes expropriation of the People a dominant strategy for the Elite whenever a social contract does not emerge in equilibrium. Since from Proposition 1 this is the best option also for the People, a democratic social contract emerges with the support and consensus of all social groups.

The scenarios of the democratic transition, the occurrence of violent conflicts and their implication for the emergence of a social contract are summarized in,

Proposition 3 (Democratization, Violent Social Conflicts and the Social Contract). The economy is characterized by an endogenous democratization that

- follows a violent social conflict if $\gamma \leq \bar{\gamma}(c, x, \varphi)$, and leads to a social contract only if $\underline{\gamma}(c, x, \varphi) \leq$ $\gamma \leq \bar{\gamma}(c, x, \varphi){ }^{37}$

- is peaceful and leads to a social contract if $\gamma \geq \bar{\gamma}(c, x, \varphi) .{ }^{38}$

In terms of stability of democracies, notice that the Elite has no incentives to attempt regaining the control of the state apparatus after a peaceful democratic transition since the transition to democracy takes place in the absence of any real threat of conflict by part of the disenfranchised. Peaceful democratization therefore leads to high quality and stable democracies. This is not the case after a violent democratic transition, however, that occurs since the Elite does not accept to give up the power. In this case violent attempts to regain the power by part of the former ruling group can be expected. Finally, notice that the analysis has imposed some parametric assumptions that allowed to illustrate the taxonomy with all possible democratization scenarios that can arise in the model. Some of these scenarios may not emerge as equilibrium outcomes under different parametric restrictions, however. In particular, if the cost of conflict is so large to the point that a threat of conflict to implement a social contract is never credible, then the scenario with a violent conflict followed by a social contract cannot emerge. Similarly no peaceful democratization can be observed if the distortions from rent extraction are sufficiently low no peaceful democratization since the Elite never finds it optimal to accommodate democratization in the absence of a violent conflict overthrowing them. ${ }^{39}$

\footnotetext{
37 The transition takes place only when $\lambda_{t} \leq \Upsilon(\gamma)$ and $\lambda_{t} \leq \bar{\Lambda}_{E}(\gamma)$, respectively, and if the elite are defeated.

${ }^{38}$ In this case democratization finds unanimous support in the population as soon as $\lambda_{t} \leq \underline{\Lambda}_{E}(\gamma)$.

${ }^{39}$ These issues are discussed in details in the Appendix.
} 
Before turning to the empirical investigation of the novel implications of the model, few remarks are in order. Despite its simplicity, the theory delivers several predictions about the determinants and consequences of democratization. In terms of determinants of the transition scenario, the model predicts that some structural features should be relevant. From Proposition 3, for given $\underline{\gamma}(c, x, \varphi)$ and $\bar{\gamma}(c, x, \varphi)$, the democratization scenario depends on the level of $\gamma$. The literature suggests that these structural features are likely to be related to (geographical and historical) country specific conditions, as discussed in the introduction. The taxonomy of democratization scenarios and the implications for the quality of emerging democracies do not depend on the actual assumptions about the changes in income inequality. Assuming a monotonic change in inequality implies that democratization is eventually inevitable and its timing is deterministic. This assumption is made only to simplify illustration, since the predictions concerning the different types of democratization are unchanged even if the evolution of technological progress and inequality are non-monotonic and stochastic. The only difference would be that the very occurrence of democratization, and its actual timing, would also be uncertain. ${ }^{40}$ The theory further predicts that the scenario also depends on the parameters $x, \varphi$ and $c$, which capture the rent-extraction ability of the ruler, the distortions associated with the lack of a social contract and the cost of failed conflicts, respectively. These parameters are likely to be related to both, time invariant, country specific features and time variant, and possibly stochastic, short term contingencies like economic shocks related to local production or external shocks related to the international context. Furthermore, we did not consider any random variable affecting the conflict potential of ruler and ruled or changes in the perceived probability that the conflict will be successful. It is easy to show, however, that the thresholds affecting the democratization scenario shift depending on random contingencies that temporarily affect the conflict potential, or their perception, by part of each group. Consequently, while the model suggests a key role of time invariant country specific characteristics, it also suggests that both the transition scenario and its timing is likely to be strongly affected by short term contingencies and random events. ${ }^{41}$

The most interesting novel, prediction of the model concerns the consequences of the different transition scenarios, however. In this respect, the theory predicts that the level of inequality, the size of the elite and the other parameters do not have a primary role for consequences of democratization

\footnotetext{
${ }^{40} \mathrm{~A}$ second difference would be that in the presence of stochastic and non monotonic dynamics one could also study the role of the democratization scenario for the stability and the consolidation of democracies in more details.

${ }^{41}$ For instance the recent evidence by Ciccone and Brückner (2011) and Ciccone, Brückner, and Tesei (2011) documents the role of negative income shocks and oil price variations for triggering democratic transitions. Miguel, Satyanath, and Sergenti (2004) and Ciccone and Brückner (2010) find that negative income shocks (instrumented by changes in precipitations) and changes in the international commodity prices, respectively, affect the likelihood of observing civil conflicts in Sub-Saharan Africa.
} 
above and beyond the transition scenario. ${ }^{42}$ The type of transition scenario should therefore be of primary importance to explain the features of the emerging democracies.

\section{Empirical Relevance}

The main testable, and so far empirically unexplored, prediction concerns the role of the transition scenario, in terms of the presence or absence of violent conflicts during democratization, for the quality of the emerging democracies. In the following, we test this prediction by exploring the role of violent social conflicts using data for the "third wave" of democratization according to the terminology of Huntington (1993).

Data. The analysis exploits the different years of democratization in the countries that democratized during the "third wave" after 1970, in order to isolate the role of democratization. The main information on democratization events and the year of democratization is taken from Papaioannou and Siourounis (2008), who developed a binary democratization indicator from an improved coding of democratization during the third wave based on available data sources. A detailed chronology of democratization events can be found in their Table 1. The coding of democratic transition is based on relevant changes in political freedom leading to free and contested elections. ${ }^{43}$

As main dependent variable of interest we use the Civil Liberties index provided by Freedom House as measure of institutional quality, for which data are available for the period 1972-2003. ${ }^{44}$ The Civil Liberties index is an aggregate index providing summary information about relevant indicators that relate to the concept of social contract and quality of democracy that has been modeled in the theory. These include information on freedom of assembly, demonstration, public discussion, the possibility to form political parties and organizations, religious institutions and and the existence of independent media that relate to the political freedom. The index also includes information on the protection from misappropriation by the ruling group in terms of independent judiciary, rule of law, protection from terror, freedom from government corruption, state control of travel and employment and the protection

\footnotetext{
${ }^{42}$ Proposition 3 implies, for instance, that for any $\gamma \geq \bar{\gamma}(c, x, \varphi)$, a social contract emerges irrespective of the actual levels of $\gamma$, the ability to extract resources $x$ and the distortions $\varphi$ in the absence of a social contract.

${ }^{43}$ The classification follows the conceptualization of Munck and Verkuilen (2002) and use sizable changes in the Freedom House or Polity indicators together with information from political, historical and election databases. To identify permanent democratic transition it further imposes a five-year stability condition. We refer to Papaioannou and Siourounis (2008) for a detailed description of the methodology used for the classification.

${ }^{44}$ Alternative measures of quality of democracies in terms of rule of law, law and order, and of measures against corruption are provided by ICRG. These measures could also be suitable to test the predictions of the theory but cannot be used for our purposes since the empirical strategy exploits democratization events starting in the early 1970s, while the ICRG data only go back to 1984 .
} 
of the right to private business and initiative, which are more specifically related to economic liberties and the protection against expropriation by part of the ruler. The aggregate index takes values from 1 to 7 , with 1 representing the most free and 7 representing the least free. Countries with a rating of 1 generally have an established and equitable rule of law with free economic activity, a rating of 2 indicates some deficiencies, ratings of 3, 4, or 5 may indicate partial compliance with all of the elements of civil liberties, countries with a rating of 6 enjoy partial rights and restricted business activity, and a rating of 7 indicates virtually no freedom. ${ }^{45}$

Data on the extent of violence during the democratic transition are collected from different sources. As benchmark we use the data from the UCDP/PRIO Armed Conflict Dataset and from Freedom House. ${ }^{46}$ Using the PRIO data, violence is coded as binary variable if a country experiences any incidence of civil conflict in a given year with more than 25 battle related deaths. This definition of conflict includes internal and internationalized social conflicts (which may include also interventions from international organizations or foreign countries). A more restrictive measure focus on internal conflicts.An alternative data source for violence during the process of democratization is the Freedom House dataset by Karatnycky (2005) that codes the violence during the democratic transition in four different intensities: nonviolent, mostly nonviolent, significant violence, and high violence. In the empirical analysis, we present results that exploit the variation across all four levels of intensity, as well as binary variables indicating substantial violence during the transition.

The benchmark data set consists of an unbalanced sample of 173 countries over the period 19722003 for which we have 4,934 country-year observations. There are 61 permanent democratization events on which the main analysis is based. ${ }^{47}$ The civil liberties index is bounded between 1 and 7 (with lower values indicating a higher degree of civil liberties), with a mean of 4.02 (standard deviation 1.94). Table 1 presents the correlations between the variables of interest. As one would expect, democratization (in terms of a binary variable that takes value 0 in all years before and 1 in all years after democratization) is associated with a greater degree of civil liberties, while armed conflict has the opposite correlation. There also appears to be a negative (but fairly small) negative

\footnotetext{
${ }^{45}$ According to Freedom House a poor rating for a country "is not necessarily a comment on the intentions of the government, but may indicate real restrictions on liberty caused by non-governmental terror.", which represents a suitable definition of institutional quality to test the model predictions where good quality democracies are reflected by a social contract requiring widespread adherence from all the different interest groups in the society.

${ }^{46}$ The UCDP/PRIO Armed Conflict Dataset is the version v.4-2010, 1946 2009, based on and updated by Harbom and Wallensteen (2010). The data and a detailed data description are available at http://www.pcr.uu.se/research/UCDP/data_and_publications/datasets.htm. The alternative data source is the Freedom House Study edited by Karatnycky (2005).

${ }^{47}$ See Papaioannou and Siourounis (2008) for details on the definition of permanent democratization.
} 
correlation between democratization and armed conflict. Considering income variables, it turns out that higher growth and larger income are associated with better civil liberties, and less conflict, and there is a weak correlation with democratization.

Preliminary Analysis: Determinants of Democratization As a preliminary investigation we check whether the relationship between inequality and the likelihood of social conflicts already documented in the literature, as discussed above, also emerges during the democratic transitions of the third wave. Table 2 reports the results of cross-country regressions with one observation per country. The dependent variable in a linear probability framework is a binary indicator variable of a violent transition, which is regressed on different measures of inequality before the transition, as well as other controls. The data on income inequality (in form of Gini indices) is only available over five years intervals and is taken from the World Income Inequality Database (WIID). To account for the role of pre-transitional inequality for the democratization scenario we consider income inequality in the five year period before the democratic transition in a each country. We also control for on GDP per capita (data from the World Development Indicators), for the presence of Ethnic Tensions (ICRG) and for Ethno-linguistic and Religious Polarization (Montalvo and Reynal-Querol, 2005). ${ }^{48}$ For a small subset of the countries, we also have access to proxies for land inequality constructed Muller and Seligson (1987), which measure the share of agricultural population without land around 1970, that is, before the third wave of democratization began.

The results in Table 2 indicate that higher inequality before the transition tends to significantly increase the likelihood of a violent transition. The findings are robust to the inclusion of the level of civil liberties before the democratic transition and additiona controls. ${ }^{49}$ Interestingly, once inequality is controlled for neither income per capita nor civil liberties before the transition appear to be significant determinants of the likelihood of observing violence during the democratic transition. Column (8) provides some indication that also the share of landless is related to the likelihood of violence although these results should be interpreted with caution given the restricted sample size. It is important to notice that, strictly speaking, the results of Table 2 cannot be directly interpreted in light of the theoretical taxonomy, which characterizes the occurrence of violent conflicts as a function of structural inequality (the variable $\gamma$ capturing the concentration in the control of natural resources or the size

\footnotetext{
${ }^{48}$ The measure of Ethnic Tensions is taken from ICRG; lower scores indicate countries where racial and nationality tensions are high because opposing groups are intolerant and unwilling to compromise, while higher scores indicate countries where tensions are minimal. All ethnic tension and polarization variables are time invariant.

${ }^{49}$ The specification in columns (3) and (4) is identical, but column (4) presents results restricted on the sample of countries for which additional information civil liberties before the transition, ethnic tensions, and GDP, is available, i.e., restricting to countries contained in the estimation sample of columns (4) and (5).
} 
of the elite in the model) and not income inequality measured by a Gini Index. The results are, nonetheless, suggestive since it can be shown that a similar taxonomy emerges in terms of Gini Indices. ${ }^{50}$

This preliminary analysis documents that the potential role of inequality as determinant of violence during democratization appears to be in line with the theoretical implications as well as with the previous results in the literature. These results should be taken as suggestive, however, since the small sample size and the reliance on cross-country variation prevents a more detailed analysis that accounts for unobserved heterogeneity that is due to time invariant country characteristics or that is time specific, by including country and year fixed effects, respectively. ${ }^{51}$

Evidence on the Role of Violence during Democratization. The main novel testable hypothesis can be directly derived from Proposition 3 and refers to the consequences of violent and non-violent democratic transitions for the institutional quality of emerging democracies: Democracies that emerge after a violent social conflict are less likely to lead to high quality democracies that are characterized by a high degree of of Civil (economic and political) Liberties. To our knowledge, this implication has not been empirically investigated in the literature.

A look at the raw data provides some first impression about the empirical relevance of this hypothesis. Figure 1 plots the evolution of average civil liberties over the ten years before and after a permanent democratization. ${ }^{52}$ The plot distinguishes between countries that exhibited a transition to democracy that was accompanied by violent conflict in the year before or in the year of the transition, and countries in which the transition to democracy was peaceful. To interpret the Figure recall that a higher value of the index implies worse civil liberties. The overall pattern in both groups is similar and display a sizable reduction around the year of democratization. Before democratization, civil liberties are worse on average (as indicated by the positive level of the demeaned index) but they substantially improve around democratization (as indicated by the negative values of the index). This patter of civil liberties after democratization is to be expected since the classification used to identify the year of democratization requires a sufficiently large change in the political freedom and the presence of free and contested elections. Even if the dichotomous classification of democratization and the index

\footnotetext{
${ }^{50}$ The iso-gini curves are upwards sloping in the $(\gamma, \lambda)$ space since higher $\lambda$ and lower $\gamma$ increase the Gini index so that to keep its level constant higher $\lambda$ must be compensated by a lower $\gamma$. This implies that the taxonomy derived for different levels of time invariant, structural, inequality $\gamma$ could be similarly re-phrased in terms of Gini Indices.

${ }^{51}$ The main problem is that the main explanatory variable of interest, income inequality, exhibits little variation over time and is available in 5-year intervals, which essentially prevents exploiting within country variation.

${ }^{52}$ The civil liberties are time demeaned to capture global trends in civil liberties and then averaged over the respective pre- and post-transitional periods.
} 
of civil liberties do not capture the very same information, we should expect that the dichotomous classification of democratization is highly correlated to changes in the (non dichotomous) measure of quality of civil liberties. Our interest is, however, in testing the hypothesis that the transition scenario may have long lasting effects on the quality of the emerging democracy, however. Figure 1 suggest that this could be, indeed the case. There is essentially no difference in the index of civil liberties across countries with violent and non violent transitions before democratization (as indicated by the very close horizontal dashed lines). After democratization, however, there is a clear difference in the level of civil liberties. After a non-violent democratization, civil liberties are about one index point better than in the average country, corresponding to an improvement of about 1.5 index points. With a mean (standard deviation) of the index of civil liberties is 4.02 (1.94) in the sample, a transition to democracy improves the civil liberties by about three quarters of a standard deviation. Countries with violent transition experience a much less pronounced improvement in civil liberties than countries with a peaceful transition to democracy, with an improvement of about half an index point or a quarter of a standard deviation. It is interesting that the effect of violence during democratization is long lasting and does not appear to vanish during the decade after the transition. Consequently, while the average improvement in civil liberties reflects an almost tautological fact, it is interesting to see the time pattern, the quantitative extent of the improvement, and in particular the difference that the democratization scenario appears to make. The figure therefore provides a first shred of evidence pointing towards the relevance of the transition scenario. It should be noted, however, that this graphical illustration only includes countries that eventually democratize during the observation period and it is, therefore, not informative on the effect of democratization compared to countries that do not democratize in the observation period. Moreover, the data reflect averages that only account for the overall time pattern in these countries, but that do not control for any other potentially relevant covariates.

In order to test the theoretical hypothesis more rigorously, we devise an empirical strategy that follows closely the theoretical predictions. Due to the fact that the year of democratization differs across third-wave democracies, we can exploit variation across countries and over time. In particular, we estimate empirical specification,

$$
Q_{i, t}=\delta \text { Democ }_{i, t}+\zeta \text { ViolentDemoc }_{i, t}+\alpha_{i}+\eta_{t}+X_{i, t-1}^{\prime} \Gamma+\varepsilon_{i t}
$$

where the dependent variable $Q_{i, t}$ reflects the institutional quality in terms of the extent of civil liberties in country $i$ in year $t$. The variables Democ and ViolentDemoc represent binary variables that take value 1 in the year of, and all years after, a permanent democratization episode or a permanent democratization episode that does involve civil conflict, respectively. The coefficients of primary 
interest are $\delta$, which captures the effect of democratization, and $\zeta$, which estimates the distinct effect of democratization when it is associated with a violent conflict. The estimation includes country and time fixed effects, $\alpha_{i}$ and $\eta_{t}$, respectively, to account for time-invariant country characteristics and for time trends that are common across countries.

Due to the inclusion of country and year fixed effects, $\delta$ represents a treatment effect of democratization in the sense of a difference-in-difference estimator that exploits a democratic transition in the respective countries as treatment (first difference) and compares it to the development in countries that do not experience a transition, i.e., that stay democratic or autocratic (second difference). In addition, $\zeta$ represents a further treatment effect of violence during the transition on this effect. In other words, $\zeta$ reflects a triple-difference (difference-in-difference-in-differences) estimator that indicates how the democratization effect varies when the democratic transition is associated with civil conflict.

The vector $X$ includes additional controls, such as an indicator of civil conflict in country $i$ in year $t$ or $t-1$ to control for direct effects of violence on institutional quality measured by the Civil Liberties Index, or past income levels, income growth, or region specific growth trends to account for economic influences that may matter for institutional improvements. The error term, $\varepsilon_{i t}$, is allowed to follow a country-specific autoregressive process. Standard errors account for heteroskedasticity clustered on the country-level.

The empirical model (11) is specified closely along the lines of the theoretical predictions, according to which the major determinant of institutional quality after democratization is the transition scenario. As consequence of Proposition 3, the level of time invariant characteristics (like, e.g., $\gamma, x$ or $\varphi$ ) or changes in inequality $(\lambda)$ over time do not matter for the emergence of a social contract, that is, for the level of civil liberties, beyond their role in influencing the democratization scenario. The empirical specification (11) explicitly accounts for the potential direct role of time invariant country characteristics, like, e.g., $\gamma$, by including country fixed effects, while potential direct effects of economic development, including technological change, economic development and $\lambda$, are captured by the timevarying controls $X$.

The interpretation of the effects $\delta$ and $\zeta$ as causal requires several critical assumptions to be satisfied. First, for the estimates to be unbiased, the reform variable (peaceful and violent democratization, respectively) have to be strictly exogenous conditional on the observable characteristics. Country fixed effects and year fixed effects, as well as additional controls in the vector $X$ should account for the main influences predicted by the theory. Reverse causality is unlikely in the context of institutional quality, that is typically determined by the political regime and, in particular, democratization, see 
e.g. Giavazzi and Tabellini (2005). To account for a possible direct role of past civil liberties we also test an extensive specification of equation (11), by including lags of the dependent variable. This should help accounting for this potential confound.

The empirical results are presented in Tables 3, 4 and 5. Table 3 presents the results for the most parsimonious baseline specification that reflects the empirical model (11) but only includes country and year fixed effects as additional controls. Columns (1) and (2) suggest that democratization, regardless of whether it was associated with violence or not, has a significant negative effect on the civil liberties index. Recalling that the index takes larger values for worse protection of civil liberties the result implies, as expected, that democratization leads to improved civil liberties. The magnitude of the effect is somewhat smaller, but still statistically significant, if past civil liberties (lagged by one year) are included as a control, as indicated by the results in column (2). Column (3) presents the results when distinguishing between democratic transitions without and with violence in the year of, or prior to, democratization, where violence is measured as any incidence of conflict using the PRIO data. The results show a substantially larger improvement in civil liberties after a peaceful democratization, compared to the average (pooled) results in Columns (1) and (2). At the same time, violent transitions exhibit a deterioration of institutional quality compared to countries with a peaceful transition to democracy. This finding emerges consistently throughout all specifications, regardless of whether conflict incidence in a particular year is added as additional control, or whether lagged institutional quality is controlled for. Columns (7)-(10) repeat the same analysis when restricting attention to internal conflicts about government only. ${ }^{53}$ It is noteworthy that the finding is robust to controlling for the incidence of violent conflicts in each period (i.e., before as well as after democratization). As one might expect, the occurrence of a social conflict in a certain period reduces civil liberties. A more interesting observation is that on top of controlling for armed conflicts in each period, the occurrence of violence during the democratic transition persistently and significantly reduces civil liberties compared to peaceful transitions to democracy. The results are qualitatively identical when controlling for past institutional quality, or when applying alternative estimation methods. ${ }^{54}$ Table 4 presents results for an extended specification that also includes income controls (in terms of growth in GDP per capita lagged by one and two years, as well as log GDP per capita lagged by three years) and region specific trends in growth of GDP per capita. The results are qualitatively identical in

\footnotetext{
${ }^{53}$ While the more general conflict definition includes internationalized internal armed conflicts that occur between the government of a state and internal opposition groups with potential intervention from other states the more restrictive definition refers to internal armed conflicts between the government of a state and internal opposition groups only without intervention from other states.

${ }^{54}$ In particular, the results are qualitatively similar when estimating fixed effects ordered logit models using the methodology proposed by Baetschmann, Staub, and Winkelmann (2011). Results are available upon request.
} 
the extended specifications and document that violent transitions display a significant deterioration compared to non violent ones.

Finally, Table 5 presents corresponding results when using the Freedom House classification of violence during the democratic transition in third wave democracies, see Karatnycky (2005). Columns (1)-(4) present results when distinguishing between transitions with high violence from transitions with no or modest violence. Again, democratic transitions with little or no violence imply a significant improvement in institutional quality in terms of the civil liberties index, as indicated by the negative coefficient. Violent transitions, on the other hand, have a significantly worse effect on institutional quality. Columns (5)-(8) display the results when using all four levels of violence coded in the Freedom House data set, where democratic transitions with no violence at all represent the reference group. Consistent with the previous results, democratic transitions with no violence imply a significant improvement of institutional quality (in terms of a reduction of the civil liberties index). The effect is similar in countries with little of some violence during the transition, but much weaker in countries with high violence during the transition.

\section{Concluding Remarks}

This paper has addressed the question why some democracies provide a relatively poor protection of individual liberties in the political and economic domains. A partial answer to this difficult question can possibly be found by explicitly considering the role of the very different paths followed by the different countries during their transition towards democracy. In particular, the type of transition and the level of violence during the regime transition can help explaining part of the persistent differences in the quality of civil liberties in the emerging democracies.

A simple theoretical model is offered to study the different democratization scenarios within a unified framework. The theory characterizes the conditions under which democracies endogenously arise and to study their consequences of for the quality of democracies. Dynamically, the politicoeconomic equilibrium is initially characterized by a non democratic regime which persists as long as it represents the best option for the ruling elite which, at the same time, has to be sufficiently strong to retain power. The model features endogenous democratization which can be either peaceful or involve open conflict depending on the relative (fighting) power and the relative interests of the different social (and economic) groups. The transition scenario has important implications for the likelihood of the emergence of high quality democracies (which are modeled as equilibrium social contracts) in terms of the degree of civil liberties. Violent transitions are less likely to implement high quality democracies than peaceful transitions. This testable hypothesis is investigated using cross-country 
panel regressions by exploiting information on the different timing of democratization in countries of the third wave of democratization. Using a difference-in-differences approach, the results document that the effect of democratization on civil liberties is significantly (and persistently) weaker in countries that experienced violent, rather than peaceful, transitions. The results are robust to several checks like controlling for the occurrence of violent conflicts (beyond violence during democratization) the lagged values of civil liberties and several relevant covariates.

Many issues remain open and the analysis suggests some potentially interesting avenues for future research. The transitional scenario, and the violence involved, may have a persistent effect on other key outcomes like, for instance, income growth, the effectiveness of public policies or the degree of political corruption. A related, direction for future research would be to further investigate implications of the transition scenario for the stability and consolidation of democracy. While the theory suggests that democracies emerging out of violence may also be less stable this prediction is not tested in the empirical analysis since the econometric identification exploits the timing of permanent transitions to democracy. Finally, the model and the empirical analysis have relied on a dichotomous representation of political regimes and type of transition (violent and peaceful) while accounting for a non dichotomous measure of the quality of democracy (civil liberties). Recent research suggests, however, the emergence and consolidation of hybrid regimes which could also be related to the different democratization scenario. 


\section{References}

Acemoglu, D. (2008): "Oligarchic versus Democratic Societies," Journal of the European Economic Association, 6(1), 1-44.

Acemoglu, D., S. Johnson, and J. Robinson (2001): "The Colonial Origins of Comparative Development: An Empirical Investigation," American Economic Review, 91(5), 1369-1401.

Acemoglu, D., S. Johnson, J. Robinson, and P. Yared (2008): "Income and Democracy," American Economic Review, 98(3), 808-842.

Acemoglu, D., and J. Robinson (2000): "Why Did the West Extend the Franchise? Democracy, Inequality, and Growth in Historical Perspective," Quarterly Journal of Economics, 115(4), 116799.

(2001): “A Theory of Political Transitions," American Economic Review, 91(4), 938-63.

(2006): Economic Origins of Dictatorship and Democracy. Cambridge University Press, Cambridge.

Aristotle (1992): The Politics (translated by T.A. Sinclair). Penguin, London.

Baetschmann, G., K. E. Staub, and R. Winkelmann (2011): "Consistent Estimation of the Fixed Effects Ordered Logit Model," IZA Discussion Paper, 5443.

BArro, R. J. (1999): "Determinants of Democracy," Journal of Political Economy, 107(6), S158S183.

(2000): "Rule of Law, Democracy, and Economic Performance," in 2000 Index of Economic Freedom, ed. by M. Miles, and et al. The Heritage Foundation, Washington.

Bertocchi, G., and M. Spagat (2001): "The Politics of Cooptation," Journal of Comparative Economics, 29, 591-607.

Besley, T., And T. Persson (2011): "The Logic of Political Violence," Quarterly Journal of Economics, forthcoming.

Blattman, C., and E. Miguel (2010): "Civil War," Journal of Economic Literature, 48(1), 3-57.

Boix, C. (2003): Democracy and Redistribution. Cambridge University Press, Cambridge.

Boix, C., And S. C. Stokes (2003): "Endogenous Democratization," World Politics, 55(4), 1-48. 
Bourguignon, F., And T. Verdier (2000): "Oligarchy, Democracy, Inequality and Growth," Journal of Development Economics, 62(2), 285-313.

Brownlee, J. (2009): "Portents of Pluralism: How Hybrid Regimes Affect Democratic Transitions," American Journal of Political Science, 53(3), 515-532.

Cederman, L.-E., S. Hug, and L. F. Krebs (2010): "Democratization and Civil War: Empirical Evidence," Journal of Peace Research, 47(4), 1-18.

Cederman, L.-E., S. Hug, and A. Wenger (2008): "Democratization and War in Political Science," Democratization, 15(3), 509-524.

Cervellati, M., P. Fortunato, and U. Sunde (2007): "Consensual and Conflictual Democratization, Rule of Law, and Development," CEPR DP 6328.

(2008): "Hobbes to Rousseau: Inequality, Institutions, and Development," Economic Journal, 118, 1354-1384.

Cheibub, J. A., J. Gandhi, and J. Vreeland (2010): "Dictatorship and Democracy Revisited," Public Choice, 143(1).

Cheibub, J. A., And J. R. Vreeland (2010): "Economic Development and Democratization," in Dynamics of Democratization, ed. by N. Brown. Johns Hopkins University Press, Baltimore.

Ciccone, A., And M. BrüCKner (2010): "International Commodity Prices, Growth, and Civil War in Sub-Saharan Africa," Economic Journal, forthcoming.

(2011): "Rain and the Democratic Window of Opportunity," Econometrica, forthcoming.

Ciccone, A., M. BrüCkner, and A. Tesei (2011): "Oil, Income, and Democracy," Review of Economics and Statistics, forthcoming.

Collier, P., And A. Hoeffler (2004): "Greed and Grievance in Civil War," Oxford Economic Papers, 56(4), 563-595.

Conley, J. P., And A. Temimi (2001): “Endogenous Enfranchisement when Groups' Preferences Conflict," Journal of Political Economy, 109(1), 79-102.

De Tocqueville, A. (1835): Democracy in America. Gosselin, Paris.

DoH, C. S. (1994): "Review: On the Third Wave of Democratization: A Synthesis and Evaluation of Recent Theory and Research," World Politics, 47(1), 135-170. 
Easterly, W. (2001): "The Middle Class Consensus and Economic Development," Journal of Economic Growth, 6(4), 317-335.

Engerman, S. L., And K. L. Sokoloff (2001): "The Evolution of Suffrage Institutions in the New World," NBER Working Paper, 8512.

Epstein, D. L., R. H. Bates, J. Goldstone, I. Kristensen, and S. O’Halloran (2006): "Democratic Transitions," American Journal of Political Science, 50(3), 551-569.

Fearon, J. D. (2006): "Self-Enforcing Democracy," mimeo, available on www.academia.edu.

Fearon, J. D., And D. D. Laitin (2003): "Ethnicity, Insurgency, and Civil War," American Political Science Review, 97(1).

Field, B. (2004): "Modes of Transition, Internal Party Rules, and Levels of Elite Continuity: A Comparison of the Spanish and Argentine Democracies," Centre for the Study of Democracy, WP 0403.

Flores, T. E., And I. Nooruddin (2009): "Democracy under the Gun: Understanding Post-Conflict Recovery," Journal of Conflict Resolution, 53(1).

Giavazzi, F., And G. Tabellini (2005): "Economic and Political Liberalizations," Journal of Monetary Economics, 52(6), 1297-1330.

Glaeser, E., R. LaPorta, F. Lopez-De-Silanes, and A. Shleifer (2004): "Do Institutions Cause Growth," Journal of Economic Growth, 9, 271-303.

Gleditsch, N. P., P. Wallensteen, M. Eriksson, M. Sollenberg, and H. Strand (2002): “Armed Conflict 1946-2001: A New Dataset," Journal of Peace Research, 39(5), 615-637.

Goldstone, J. A., R. H. Bates, D. L. Epstein, T. R. Gurr, M. B. Lustik, M. G. Marshall, J. Ulfelder, And M. Woodward (2010): "A Global Model for Forecasting Political Instability," American Journal of Political Science, 54(1), 190-208.

Gradstein, M. (2007): "Inequality, Democracy, and the Protection of Property Rights," Economic Journal, 117(516), 252-269.

Harbom, L., and P. Wallensteen (2010): “Armed Conflict 1946-2010," Journal of Peace Research, 47(4), forthcoming.

Huber, E., D. Rueschemeyer, and J. Stephens (1993): "The Impact of Economic Development on Democracy," Journal of Economic Perspectives, 7, 71-85. 
Huntington, S. P. (1993): The Third Wave: Democratization in the Late Twentieth Century. University of Oklahoma Press, Oklahoma.

JaCk, W., And R. Lagunoff (2006a): "Dynamic Enfranchisement," Journal of Public Economics, $90(4), 551-572$.

(2006b): "Social Conflict and Gradual Political Succession: An Illustrative Model," Scandinavian Journal of Economics, 108(4), 703-725.

Karatnycky, Adrian, E. A. (2005): How Fredom Is Won: From Civic Resistance to Durable Democracy. Freedom House, New York.

LIPSET, S. M. (1959): "Some social requisites of democracy: economic development and political legitimacy," American Political Science Review, 53(3), 69-105.

Lizzeri, A., And N. Persico (2004): "Why did the Elites Extend the Suffrage? Democracy and the Scope of Government, with an Application to Britain's 'Age of Reform'," Quarterly Journal of Economics, 119(2), 707-765.

Llavador, H., And R. Oxoby (2005): "Partisan Competition, Growth and the Franchise," Quarterly Journal of Economics, 120(3), 1155-1189.

Lynn Carl, T. (1990): "Dilemmas of Democratization in Latin America," Comparative Politics, 23(1), 1-21.

Mansfield, E. D., And J. Snyder (1995): "Democratization and War," Foreign Affairs, 74(3), 79-98.

Meltzer, A. H., And S. F. Richard (1981): "A Rational Theory of the Size of Government," Journal of Political Economy, 89(5), 914-927.

Miguel, E., S. Satyanath, and E. Sergenti (2004): "Economic Shocks and Civil Conflict: An Instrumental Variables Approach," Journal of Political Economy, 112(4), 725-753.

Muller, E. N., ANd M. A. Seligson (1987): "Inequality and Insurgency," American Political Science Review, 81(2), 425-452.

Munck, G., And C. Leff (1997): "Modes of Transition and Democratization: South America and Eastern Europe in Comparative Perspective," Comparative Politics, 29(3), 343-362.

Munck, G., And J. Verkuilen (2002): "Conceptualizing and measuring democracy: evaluating alternative indices," Comparative Political Studies, 35(1), 5-34. 
Nelson, R., And E. Phelps (1966): "Investment in Humans, Technological Diffusion, and Economic Growth," American Economic Review (Papers and Proceedings), 56(2), 69-75.

North, D. C., J. J. Wallis, and B. R. Weingast (2009): Violence and Social Orders. Cambridge University Press, Cambridge.

O’Donnell, G., And P. Schmitter (1986): Transitions from Authoritarian Rule: Tentative Conclusions about Uncertain Democracies. Johns Hopkins University Press, Baltimore.

Papaioannou, E., and G. Siourounis (2008): "Democratization and Growth," Economic Journal, $118,1520-1551$.

Przeworski, A. (2004): "Economic Development and Transitions to Democracy," mimeo, NYU. (2005): "Democracy as an Equilibrium," Public Choice, 123, 253-273.

(2006): "Self-enforcing Democracy," in Handbook of Political Economy, ed. by D. Wittman, and B. Weingast. Oxford University Press, New York.

Przeworski, A., M. Alvarez, J. A. Cheibub, and F. Limongi (2000): Democracy and Development: Political Institutions and Well-Being in the World, 1950-1990. Cambridge University Press, New York.

Przeworski, A., And F. Limongi (1997): "Modernization: Theories and Facts," World Politics, $49,155-183$.

Remmer, K. (1999): "Democracy and Economic Crisis: The Latin American Experience," World Politics, 11(42).

Rigobon, R., and D. Rodrik (2005): "Rule of Law, Democracy, Openness and Income: Estimating the Interrelationships," Economics of Transition, 13(3), 533-564.

Rodrik, D., A. Subramanian, and F. Trebbi (2004): "Institutions Rule: The Primacy of Institutions over Geography and Integration in Economic Development," Journal of Economic Growth, 9, 131-165.

Rodrik, D., and R. Wacziarg (2005): "Do Democratic Transitions Produce Bad Economic Outcomes?," American Economic Review, 95(3), 50-55.

Rogowski, R., and D. MacRae (2008): "Inequality and Institutions: What Theory, History and (Some) Data Tell Us," in Democracy, Inequality, and Representation: A Comparative Perspective, 
ed. by P. Beramendi, and C. J. Anderson, chap. 11, pp. 354-386. Russel Sage Foundation, New York.

Sorensen, G. (1993): Democracy and Democratization. Boulder: Westview Press.

Sunde, U., M. Cervellati, and P. Fortunato (2008): "Are all democracies equally good? The role of interactions between political environment and inequality for rule of law," Economics Letters, $99,552-556$.

Tavares, J., and R. Wacziarg (2001): "How Democracy Affects Growth," European Economic Review, 45(8), 1341-1378.

Ward, M. D., And K. S. Gleditsch (1998): "Democratizing for Peace," American Political Science Review, 92(1), 51-62.

Weingast, B. R. (1997): "The Political Foundations of Democracy and the Rule of Law," American Political Science Review, 91(2), 245-263. 


\section{Appendix: Analytical Derivations and Proofs}

Proof of Proposition 1 and characterization of the functions $\bar{\Lambda}_{E}(\gamma), \bar{\Lambda}_{P}(\gamma)$ and $\underline{\Lambda}_{E}(\gamma)$. Consider an economy ruled by an Elite. Recall that the payoffs of the different groups are given by

$$
\widetilde{y}^{E}=\left[y^{E}+x \frac{(1-\gamma)}{\gamma} y^{P}\right](1-\varphi)
$$

and

$$
\widetilde{y}^{P}=y^{P}(1-x)(1-\varphi)
$$

The Elite prefers a social contract under democracy rather than being the ruling group if, and only if, inequality is low enough and the social contract is sufficiently efficiently enhancing, that is

$$
\left[y^{E}+x \frac{(1-\gamma)}{\gamma} y^{P}\right](1-\varphi) \leq \gamma y^{E}+(1-\gamma) y^{P}
$$

Rearranging we get,

$$
\lambda \leq \bar{\Lambda}_{E}(\gamma):=\frac{(1-\gamma)}{\gamma} \frac{(\gamma-x(1-\varphi))}{(1-\varphi-\gamma)}=\frac{1-\frac{x(1-\varphi)}{\gamma}}{1-\frac{\varphi}{1-\gamma}}
$$

The function $\bar{\Lambda}_{E}$ is increasing in $\gamma$ since,

$$
\frac{\partial \bar{\Lambda}_{E}}{\partial \gamma}=\frac{\partial}{\partial \gamma}\left(\frac{1-\frac{x(1-\varphi)}{\gamma}}{1-\frac{\varphi}{1-\gamma}}\right)>0
$$

The people always prefer a social contract under democracy to be ruled by the Elite since it is always true that $y^{P}(1-x)(1-\varphi) \leq y$ since $y^{P}<y$ and $(1-x)(1-\varphi)<1$. Therefore condition (12) is necessary and sufficient to observe a peaceful transition to social contract whenever the elite is ruling.

Next consider the derivation of the functions $\bar{\Lambda}_{P}(\gamma)$ and $\underline{\Lambda}_{E}(\gamma)$. For the people a democratic social contract is preferred to exploit their de facto power as ruling group if, and only if,

$$
\left[y^{P}+x \frac{\gamma}{1-\gamma} y^{E}\right](1-\varphi) \leq \gamma y^{E}+(1-\gamma) y^{P}
$$

Rearranging one gets,

$$
\lambda \geq \bar{\Lambda}_{P}(\gamma):=\frac{(1-\gamma)}{\gamma} \frac{(\gamma-\varphi)}{(1-\gamma)-x(1-\varphi)}=\frac{1-\frac{\varphi}{\gamma}}{1-\frac{x(1-\varphi)}{1-\gamma}}
$$

where

$$
\frac{\partial \bar{\Lambda}_{P}(\gamma)}{\partial \gamma}=\frac{\partial}{\partial \gamma}\left(\frac{1-\frac{\varphi}{\gamma}}{1-\frac{x(1-\varphi)}{1-\gamma}}\right)>0
$$

The Elite prefers a democratic social contract to being ruled by the People in the absence of a social contract if, and only if,

$$
y^{E}(1-x)(1-\varphi) \leq \gamma y^{E}+(1-\gamma) y^{P}
$$

and rearranging we get,

$$
\lambda \leq \underline{\Lambda}_{E}(\gamma):=\frac{1-\gamma}{[(1-x)(1-\varphi)-\gamma]}
$$


with,

$$
\frac{\partial \underline{\Lambda}_{E}(\gamma, \varphi, x)}{\partial \gamma}=\frac{\gamma-(1-x)(1-\varphi)+1-\gamma}{[(1-x)(1-\varphi)-\gamma]^{2}}=\frac{x(1-\varphi)+\varphi}{[(1-x)(1-\varphi)-\gamma]^{2}}>0
$$

Finally notice that $\bar{\Lambda}_{E}(\gamma)$ lies above $\bar{\Lambda}_{P}(\gamma)$ if the gains derived by keeping the power (and partially expropriating the disenfranchised) are lower than the wastes related to an oligarchic regime. In particular,

$$
\bar{\Lambda}_{E}(\gamma, \varphi, x)>\bar{\Lambda}_{P}(\gamma, \varphi, x) \Leftrightarrow \varphi>x(1-\varphi) \Leftrightarrow x<\frac{\varphi}{1-\varphi} .
$$

Proof of Proposition 2 and derivation of the Functions $\Upsilon(\gamma)$ and $\Psi(\gamma)$. For the people engaging in a violent conflict to attempt getting in control of the state apparatus and rule in the absence of a social contract is profitable if, and only if,

$$
\left.\pi^{E}\left[y^{P}(1-x)(1-\varphi)(1-c)\right]+\left(1-\pi^{E}\right)\left[y^{P}+x \frac{\gamma y^{E}}{1-\gamma}\right](1-\varphi)\right] \geq y^{P}(1-x)(1-\varphi)
$$

Rearranging one gets,

$$
\left(1-\pi^{E}\right) x\left[\frac{y}{1-\gamma}\right]-\pi^{E} c y^{P}(1-x) \geq 0
$$

Using the definition of $\pi^{E}$ from (4) we have,

$$
\pi^{E}=\frac{\gamma y^{E}}{y} \quad \text { and } \quad\left(1-\pi^{E}\right)=\frac{(1-\gamma) y^{P}}{y} .
$$

Using (16) in (15) we have,

$$
\begin{aligned}
\frac{(1-\gamma) y^{P}}{y} x\left[\frac{y}{1-\gamma}\right]-\frac{\gamma y^{E}}{y} c y^{P}(1-x) & \geq 0 \Leftrightarrow \\
y^{P}\left[x-\frac{\gamma y^{E}}{y} c(1-x)\right] & \geq 0 \Leftrightarrow x \geq \frac{\gamma y^{E}}{y} c(1-x) \Leftrightarrow \frac{x}{c(1-x)} \geq \frac{\gamma y^{E}}{y}
\end{aligned}
$$

and after some manipulation, and recalling that

$$
\pi^{E}=\frac{\gamma y^{E}}{y}=\frac{\gamma y^{E}}{\gamma y^{E}+(1-\gamma) y^{P}}=\frac{\gamma \lambda}{\gamma \lambda+1-\gamma}
$$

one obtains

$$
\lambda \leq \Upsilon(\gamma):=\frac{x}{(c(1-x)-x)} \frac{(1-\gamma)}{\gamma}
$$

which is positive if, and only if, loosing out in a violent conflict is sufficiently costly: $c>\frac{x}{1-x}$ since otherwise a conflict always pays-off in expectations. If this condition holds then,

$$
\frac{\partial \Upsilon(\gamma)}{\partial \gamma}=\frac{x}{(c(1-x)-x)} \frac{-\gamma-(1-\gamma)}{\gamma^{2}}<0
$$

If the People expect a social contract to be in place in democracy then triggering a violent conflict is optimal if, and only if,

$$
\pi^{E}\left[\underline{y}^{P}(1-c)\right]+\left(1-\pi^{E}\right) y \geq y^{P}(1-x)(1-\varphi)
$$

recalling that $\underline{y}^{P}=y^{P}(1-x)(1-\varphi)$. Since from (4) we have $1-\pi^{E}=\left((1-\gamma) y^{P}\right) / y$ and manipulating the previous expression one gets,

$$
\begin{aligned}
\pi^{E}(1-x)(1-\varphi)(1-c)+(1-\gamma)-(1-x)(1-\varphi) & \geq 0 \Leftrightarrow \\
\pi^{E} & \geq \frac{(1-x)(1-\varphi)-(1-\gamma)}{(1-x)(1-\varphi)(1-c)}:=a
\end{aligned}
$$


Using the definition of $\pi^{E}$ from (4) we have,

$$
\gamma y^{E} \geq a\left(\gamma y^{E}+(1-\gamma) y^{p}\right) \Leftrightarrow \gamma \lambda \geq a(\gamma \lambda+(1-\gamma)) \Leftrightarrow(1-a) \lambda \gamma \geq a(1-\gamma)
$$

The analysis discussed in the main body refers to the most interesting case in which $a \in(0,1)$ since otherwise the threat of conflict is always, or never, binding, respectively. If $a>0$, so that $(1-x)(1-\varphi)-$ $(1-\gamma)>0$ and $a<1$ so that $(1-a)=[(1-\gamma)-(1-x)(1-\varphi) c] /[(1-x)(1-\varphi)(1-c)]>0$ then

$$
\lambda \geq \Psi(\gamma):=\frac{(1-\gamma)}{\gamma} \frac{(1-x)(1-\varphi)-(1-\gamma)}{(1-\gamma)-(1-x)(1-\varphi) c}>0
$$

with

$\frac{\partial \Psi(\gamma)}{\partial \gamma}=\frac{(b c)}{[(1-\gamma)-b c]^{2}} \frac{(1-x)(1-\varphi)-(1-\gamma)}{\gamma}+\frac{(1-\gamma)}{(1-\gamma)-(1-x)(1-\varphi) c} \frac{1-(1-x)(1-\varphi)}{\gamma^{2}}>0$

Notice that if $a>1$ then (5) cannot hold since $\pi^{E} \leq 1$. In this case no threat of conflict to implement a social contract is credible and the area with conflict and subsequent social contract (displayed in Graph 4 disappears for $\underline{\gamma} \leq \gamma \leq \bar{\gamma}$ ) disappears. In this case $\underline{\gamma}=\bar{\gamma}$. Likewise, if $a<0$, then the threat of conflict to implement a social contract, (5), always hol $\bar{d}$ and the area of peaceful transition to democracy, $\gamma \geq \bar{\gamma}$ disappears.

Proof of Lemma 1. For any $\{N, \gamma\}$, the relative income of the elite $\lambda_{t}^{E}$ is given by,

$$
\lambda_{t}=\frac{w\left(A_{t}, N\right)+h_{t} r\left(A_{t}, N\right)+(N / \gamma) \rho\left(A_{t}, N\right)}{w\left(A_{t}, N\right)+h_{t} r\left(A_{t}, N\right)}=1+\frac{N}{\gamma} \frac{\rho\left(A_{t}, N\right)}{w\left(A_{t}, N\right)+h_{t} r\left(A_{t}, N\right)} .
$$

where the factor rents equal marginal productivity as described in the text. Computing the derivative with respect to $A_{t}$ one gets,

$$
\frac{\partial \lambda_{t}}{\partial A_{t}}<0
$$

due to the fact that human capital and natural resources are substitutes, which implies $\frac{\partial \lambda_{t}}{\partial \rho\left(A_{t}, N\right)}<0$.

Proof of Proposition 3. The characterization of the parametric ranges for the different democratization scenario immediately follows from Propositions 1, 2, Corollary 1, Lemma 1 and the discussion in Section 3.1. What is left to be shown is that it is not optimal for the Elite to offer democratization when the threat that the Peole trigger a conflict gets binding.

Depending on whether $\gamma \leq \underline{\gamma}$ or $\underline{\gamma} \leq \gamma \leq \bar{\gamma}$ the Elite rationally anticipates that the People will not (respectively will) offer a democratic social contract. If $\gamma \leq \underline{\gamma}$ then in case of successful conflict, the People will rule in the absence of a social contract. In this case for the Elite it is always optimal to fight the conflict when they face a credible threat since,

$$
\pi^{E}\left[y^{E}+x \frac{(1-\gamma) y^{P}}{\gamma}\right](1-\varphi)+\left(1-\pi^{E}\right) y^{E}(1-x)(1-\varphi)>y^{E}(1-x)(1-\varphi)
$$

The reason is that by fighting they will be ruled with a probability lower than one. If $\underline{\gamma} \leq \gamma \leq \bar{\gamma}$ then in case of successful conflict a social contract emerges after democratization since as discussed in Section 3 both groups have incentives to adhere to it. Nonetheless the Elite would prefer to be the ruling group in an oligarchy. The expected payoff of conflict for the Elite is larger than the payoff for accommodating democratization if, and only if,

$$
\pi^{E}\left[y^{E}+x \frac{(1-\gamma) y^{P}}{\gamma}\right](1-\varphi)+\left(1-\pi^{E}\right) y \geq y
$$


Notice that in general this condition is not necessarily satisfied. Re-arranging we have,

$$
\pi^{E}\left\{\left[y^{E}+x \frac{(1-\gamma) y^{P}}{\gamma}\right](1-\varphi)-y\right\}>0
$$

where $\pi^{E}>0$. For $\gamma \in(\underline{\gamma}, \bar{\gamma})$ condition (22) is satisfied when the threat of conflicts gets binding, that is, for any $\lambda \in\left(\bar{\Lambda}_{E}(\gamma), \underline{\Lambda}_{E}(\gamma)\right)$. Hence also in this case the Elite prefers to fight a violent conflict rather than giving up as soon as they are credibly threatened by the People. 


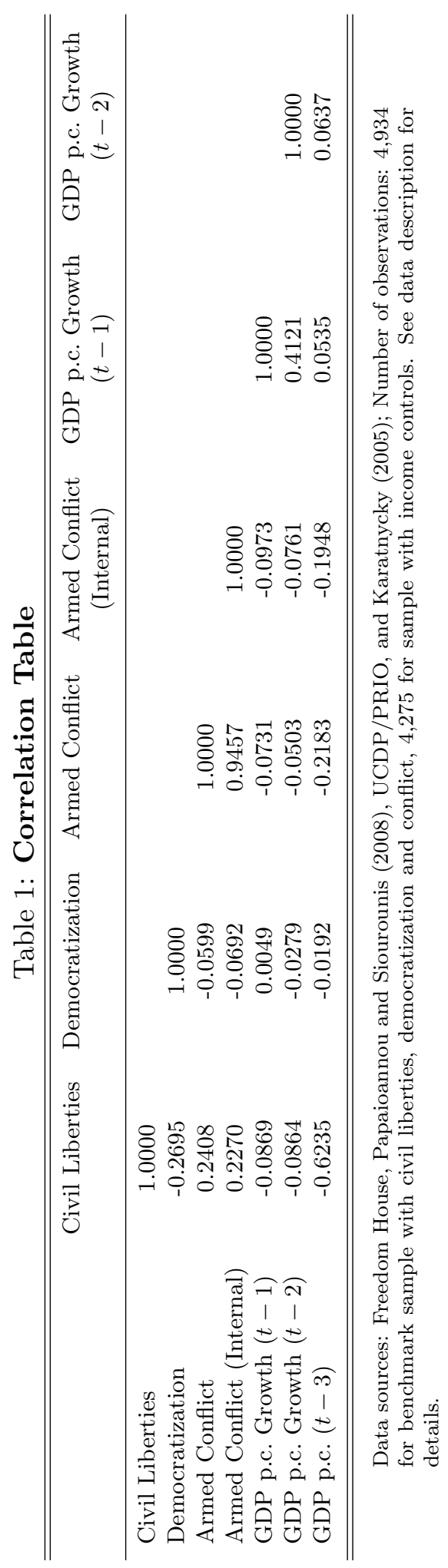




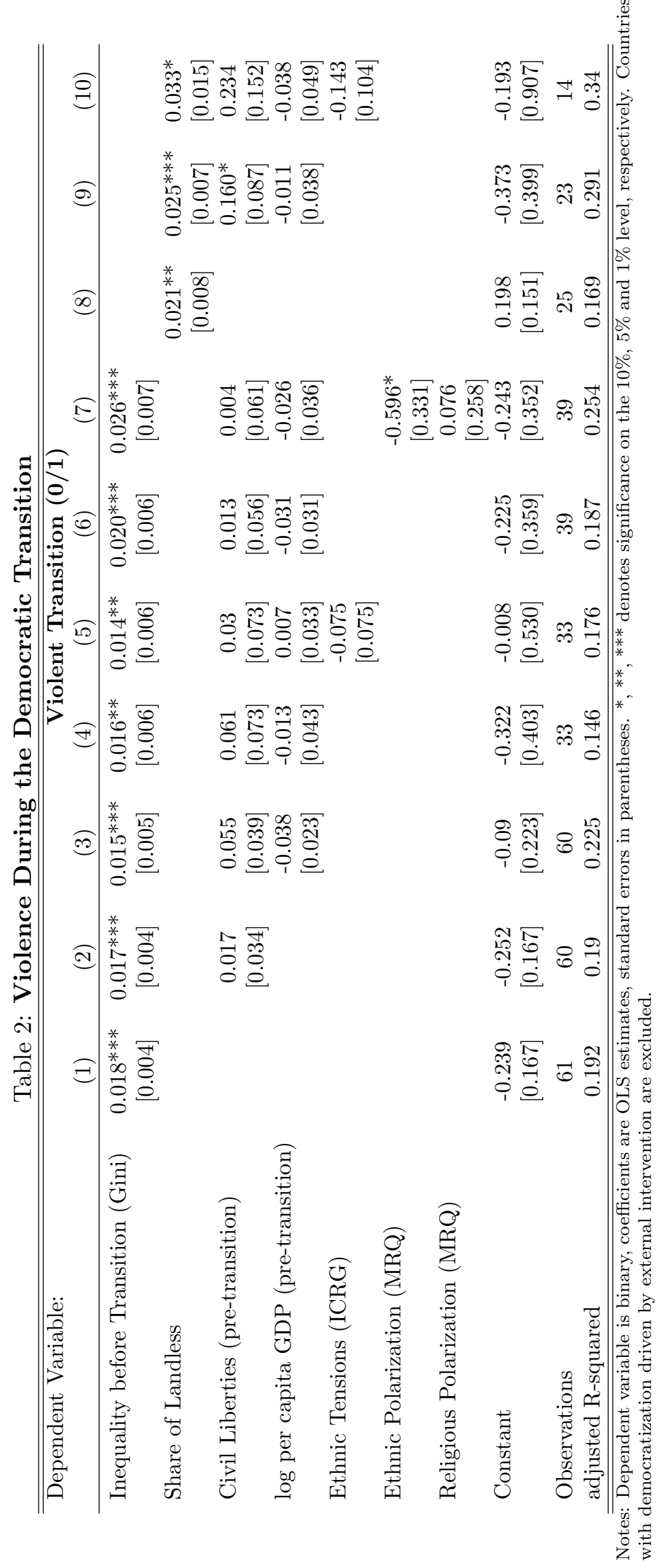




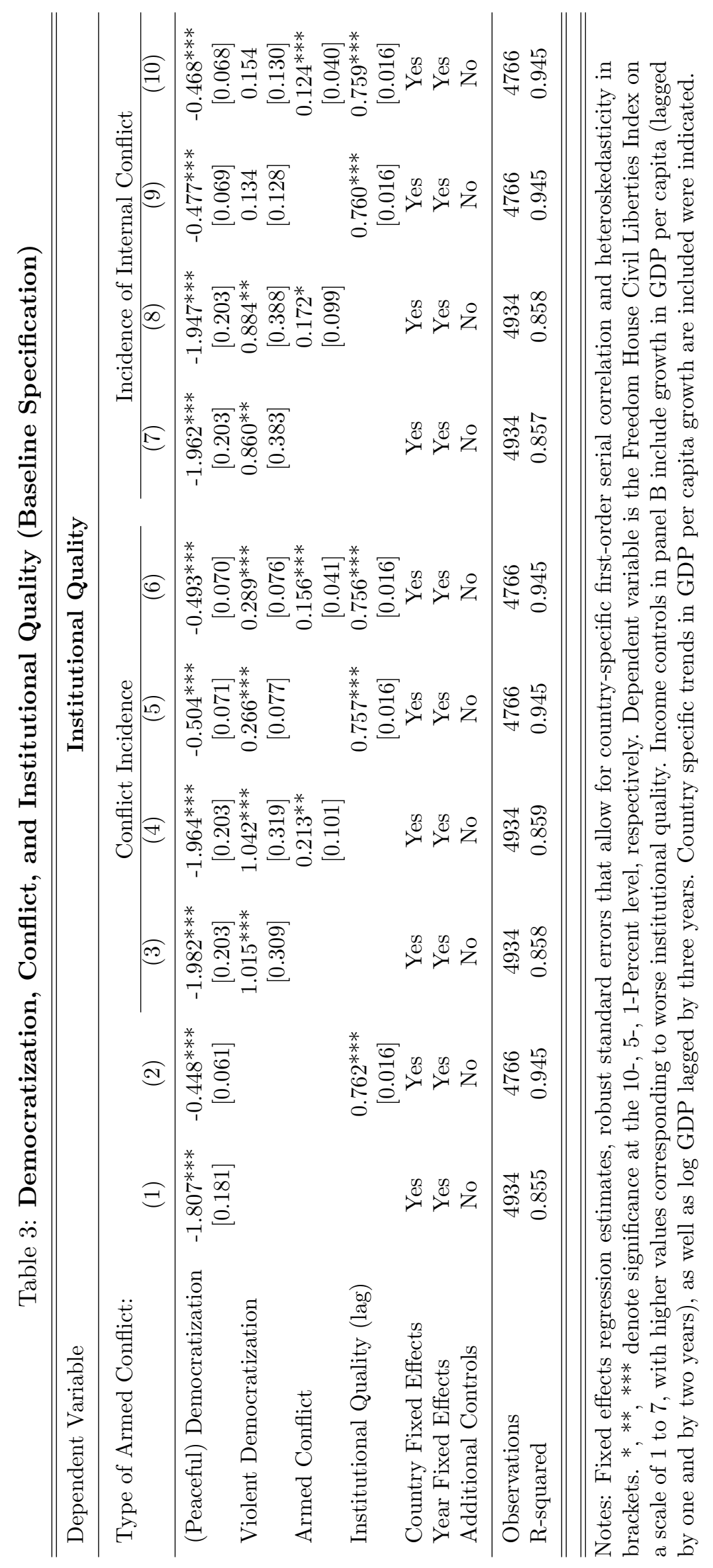




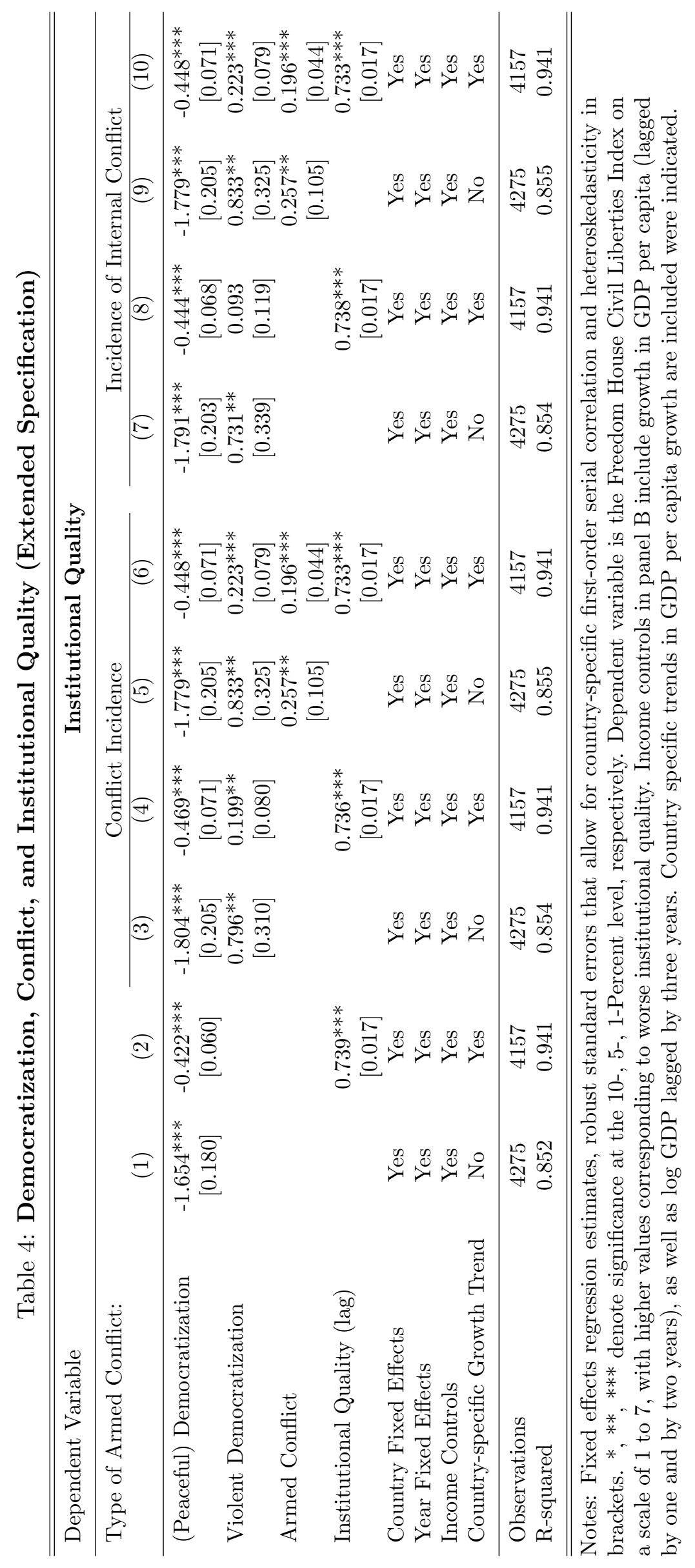




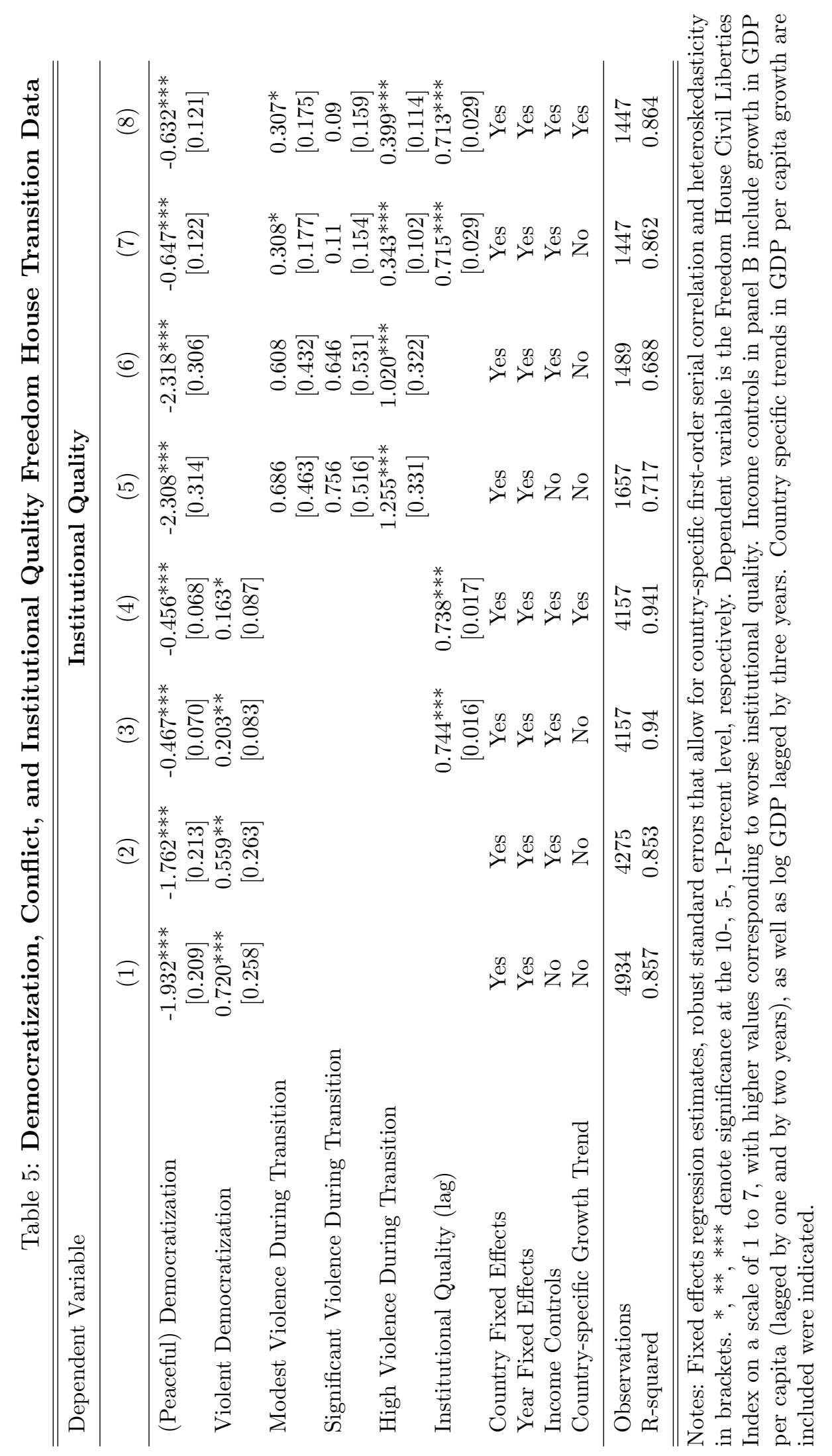


Figure 1: Civil Liberties around the Period of a Permanent Democratic Transition

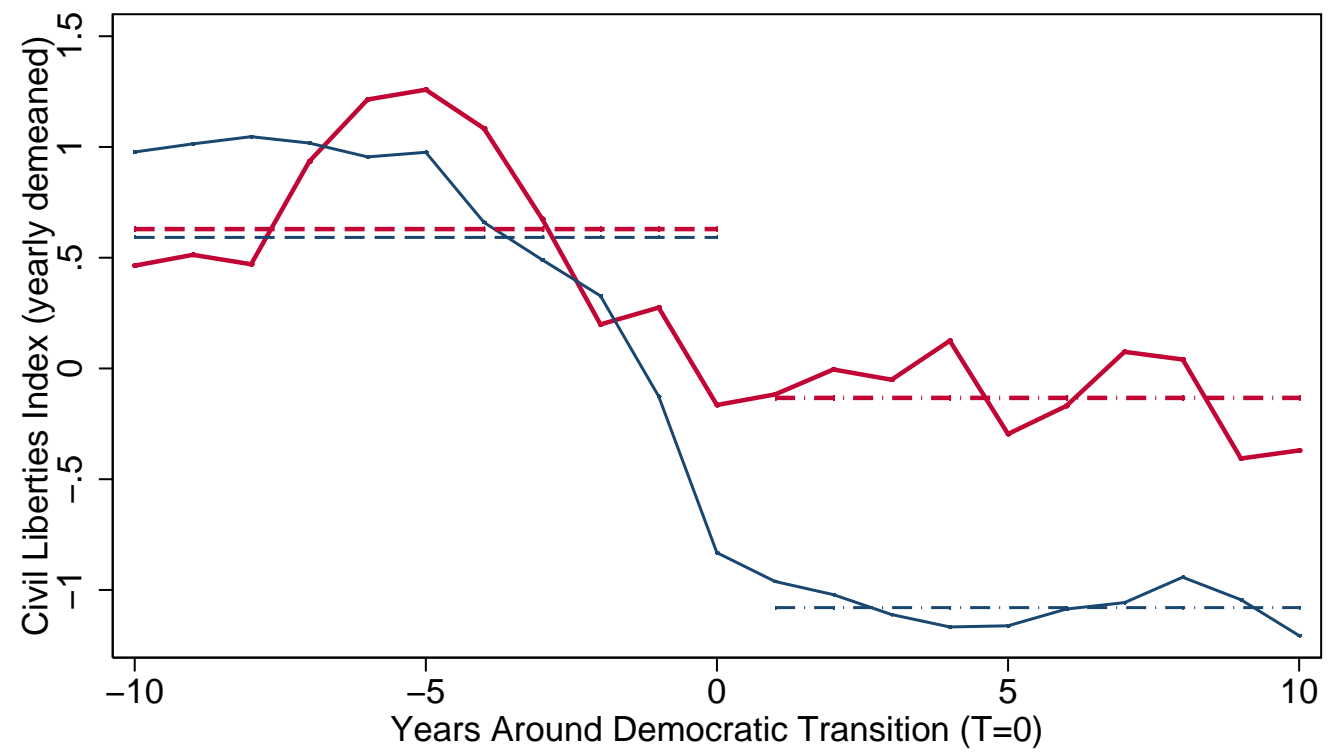

\begin{tabular}{|c|c|}
\hline ransitions & -1 \\
\hline - - - Average Before (Violent) & t) \\
\hline
\end{tabular}

The figure plots the evolution of time-demeaned levels of civil liberties (level of civil liberty index in a country minus the average level of civil liberties for that year) in the ten years before and after a permanent democratic transition. See Section 4 for details on the data sources and definitions. 